Article

\title{
Polyphenolic Profile, Antioxidant and Anti-Inflammatory Activity of Eastern Teaberry (Gaultheria procumbens L.) Leaf Extracts
}

\author{
Piotr Michel ${ }^{1}$, Anna Dobrowolska ${ }^{1}$, Agnieszka Kicel ${ }^{1}$, Aleksandra Owczarek ${ }^{1}$, \\ Agnieszka Bazylko ${ }^{2}$, Sebastian Granica ${ }^{2}$, Jakub P. Piwowarski ${ }^{2}$ and Monika A. Olszewska ${ }^{1, *}$ \\ 1 Department of Pharmacognosy, Faculty of Pharmacy, Medical University of Lodz, \\ 1 Muszyńskiego St., Lodz 90-151, Poland; E-Mails: piotr.michel@umed.lodz.pl (P.M.); \\ a.m.dobrowolska@wp.pl (A.D.); agnieszka.kicel@umed.lodz.pl (A.K.); \\ aleksandra.owczarek@umed.lodz.pl (A.O.) \\ 2 Department of Pharmacognosy and Molecular Basis of Phytotherapy, Faculty of Pharmacy, \\ Warsaw Medical University, 1 Banacha St., Warsaw 02-097, Poland; \\ E-Mails: agnieszka.bazylko@wum.edu.pl (A.B.); sgranica@wum.edu.pl (S.G.); \\ jakub.piwowarski@wum.edu.pl (J.P.P.) \\ * Author to whom correspondence should be addressed; E-Mail: monika.olszewska@umed.lodz.pl; \\ Tel.: +48-42-677-9165; Fax: +48-42-678-8398.
}

External Editor: Maurizio Battino

Received: 4 November 2014; in revised form: 28 November 2014 / Accepted: 1 December 2014 / Published: 8 December 2014

\begin{abstract}
Dry leaf extracts of eastern teaberry (Gaultheria procumbens L.) were evaluated as a source of bioactive phytocompounds through systematic activity testing and phytochemical profiling. The antioxidant efficiency was tested using five complementary in vitro models (DPPH; FRAP; linoleic acid (LA) peroxidation assay; $\mathrm{O}_{2}{ }^{--}$and $\mathrm{H}_{2} \mathrm{O}_{2}$ scavenging tests) in parallel with standard antioxidants. The $75 \%$ methanol extract and its diethyl ether, ethyl acetate (EAF), $n$-butanol and water fractions exhibited the dose-dependent responses in all assays, with the highest capacities found for EAF (DPPH $\mathrm{EC}_{50}=2.9 \mu \mathrm{g} / \mathrm{mL} ; \mathrm{FRAP}=12.8 \mathrm{mmol} \mathrm{Fe}{ }^{2+} / \mathrm{g} ; \mathrm{IC}_{50}$ for LA-peroxidation $=123.9 \mu \mathrm{g} / \mathrm{mL}$; $\mathrm{O}_{2}{ }^{-} \mathrm{SC}_{50}=3.9 \mu \mathrm{g} / \mathrm{mL} ; \mathrm{H}_{2} \mathrm{O}_{2} \quad \mathrm{SC}_{50}=7.2 \mu \mathrm{g} / \mathrm{mL}$ ). The EAF had also the highest anti-inflammatory activity in the inhibition tests of lipoxygenase and hyaluronidase $(60.14 \%$ and $21.83 \%$ effects, respectively, at the concentration of $100 \mu \mathrm{g} / \mathrm{mL}$ ). Activity parameters of the extracts correlated strongly with the levels of total phenolics $(72.4-270.7 \mathrm{mg} \mathrm{GAE} / \mathrm{g})$, procyanidins, and phenolic acids, whereas for flavonoids only moderate effects were
\end{abstract}


observed. Comprehensive UHPLC-PDA-ESI-MS ${ }^{3}$ and HPLC-PDA studies led to the identification of 35 polyphenols with a procyanidin A-type trimer, quercetin 3-O-glucuronide, isomers of caffeoylquinic acids, and (-)-epicatechin being the dominant components. Significant activity levels, high phenolic contents and high extraction yields (39.4\%-42.5\% DW for defatted and crude methanol extracts, respectively) indicate the value of eastern teaberry leaves as bioactive products.

Keywords: Gaultheria procumbens L.; antioxidant activity; anti-inflammatory activity; UHPLC-MS; HPLC-PDA; phenolic content; phenolic profile; proanthocyanidins; chlorogenic acids; flavonoids

\section{Introduction}

The Ericaceae is a large family of flowering plants with nearly worldwide distribution and many non-toxic, edible and medicinal members. The berry fruits of the Ericaceae are regarded as rich sources of bioactive phenolic compounds and like other polyphenol-rich dietary products, have attracted much attention as health-promoting antioxidant agents, exerting protective effects against the accelerated aging and certain oxidative stress- and age-related chronic diseases, including cardiovascular disease, neuro-degenerative disorders, and some types of cancer [1-6]. However, despite the fact that among dietary sources, Ericaceae berries are particularly abundant in phenolic antioxidants, they accumulate significantly lower levels of total phenolics (usually not more than $15 \mathrm{mg} / \mathrm{g}$ gallic acid equivalents, GAE, of dry weight, DW) than those observed in the leaves (usually not less than $40 \mathrm{mg} / \mathrm{g}$ GAE DW) $[7,8]$. Because of this effect and due to the seasonal availability of fresh berries, the leaves of some Ericaceae species have recently been strongly recommended as cost-effective, alternative sources of phenolic antioxidants with great potential for the prevention of chronic diseases [9-11].

Gaultheria procumbens L. (eastern teaberry, checkerberry, or American wintergreen) is an Ericaceae species native to North America and cultivated all through the Northern Hemisphere. It is an aromatic, small shrub with evergreen leaves and red berry-like fruits of wintergreen scent [12]. In traditional medicine, various tissues of $G$. procumbens and other Gaultheria species are used to treat inflammatory disorders, especially rheumatoid arthritis, swelling pain, chronic tracheitis, cold, and acute and chronic prostatitis [12]. The analgesic and anti-inflammatory activities of these plants are believed to be influenced mainly by salicylic acid derivatives, especially methyl salicylate (essential oil), acting through several mechanisms including some antioxidant effects [13,14].

Multiple oxidative stress-related effects are involved in an inflammatory process, including direct production of oxygen-centered free radicals and other ROS by stimulated immune cells. ROS in turn can activate pro-inflammatory gene expression or initiate free-radical chain reactions impairing the function of biomolecules and causing cellular injury. It is known that plant phenolics [15-17], can decrease the ROS level and limit inflammatory response through several mechanisms, especially via direct reduction of free radicals (scavenging action) and other ROS, inhibition of ROS generating pro-inflammatory enzymes, and chelation of transition metal ions [18,19]. Particularly effective are polyhydroxylated phenolics like flavonoids and proanthocyanidins [18]. Some molecules of this type, such as quercetin 
glycosides (3-O-glucoside, 3-O-galactoside, and 3-O-arabinoside), (+)-catechin, (-)-epicatechin, procyanidins $\mathrm{A} 2$ and $\mathrm{B} 2$, have been identified recently in the leaves of G. procumbens [20]. Considering their structures, these compounds could significantly affect the antioxidant and anti-inflammatory capacity of Gaultheria extracts. However, although preliminary reports for crude methanol leaf extracts of $G$. procumbens indicate promising in vitro antioxidant activity [21], no systematic quantitative study exists regarding polyphenols in this species, and no information is available about their impact on the antioxidant and anti-inflammatory activity of the leaf tissue.

Therefore, the aim of this project was to evaluate the value of G. procumbens leaves as a source of antioxidant and anti-inflammatory polyphenols. Antioxidant capacity of lipophilic (chloroform) and polar (75\% methanol) leaf extracts and their various solvent fractions was investigated by five in vitro tests of complementary mechanisms. Moreover, the anti-inflammatory activity of the extracts was studied by two methods based on the inhibition of pro-inflammatory enzymes. The fractionation process was the starting point for statistically assisted identification of the main active components of the leaf tissue. The polyphenolic profile of the plant was investigated by UV-spectrophotometric, UHPLC-PDA-ESI-MS ${ }^{3}$ and HPLC-PDA-fingerprint methods in relation to the observed activity of the extracts and a series of natural and synthetic antioxidant standards.

\section{Results and Discussion}

\subsection{Extraction Yield and Total Phenolic Content of G. procumbens Dry Leaf Extracts}

Selection of the extracting solvent is an important part of extract preparation as it affects extract composition and hence its activity. In general, alcohol and alcohol-water mixtures are considered to be the most efficient extractants for low-molecular weight polyphenols characterized by high antioxidant potential and good bioavailability [18,22]. Hydroalcoholic extracts might be also considered good representatives of traditional medicine forms like infusions or tinctures as in general they would contain similar range of constituents [23].

In this work, the composition of methanol-water mixtures was optimized to maximize recovery and antioxidant activity of the G. procumbens leaf extracts. The Folin-Ciocalteu (FC) assay was used to estimate the total phenolic content (TPC) as an indirect measure of antioxidant potential [24]. As presented in Figure 1a, the tested methanol solutions showed statistically different capacities to recover the leaf components. The highest TPC levels were obtained with $75 \%$ and $50 \%$ methanol, whereas the highest extraction yields (extract weights) were found for $25 \%, 50 \%$ and $75 \%$ methanol $(45.4 \% \pm 2.4 \% \mathrm{DW}$; analytical scale). Since the physical properties of plant extracts and their microbial stability are usually better at elevated alcohol concentration [25], 75\% methanol was chosen to prepare the crude leaf extract of G. procumbens (MEC). The semi-preparative yield of MEC from $100 \mathrm{~g}$ of the dried leaves (42.5\%) was in good accordance with the analytical data and similar to the levels (41\%-48\% DW) reported earlier for the leaves of other Ericaceae species, i.e., Vaccinium myrtilloides, Kalmia angustifolia, Arctostaphylos uva-ursi, Empetrum nigrum, and Arbutus unedo [9,20,21]. The TPC level in the MEC was $270.7 \pm 14.2 \mathrm{mg}$ gallic acid equivalents (GAE)/g DW of the extract (Figure 1b). It is of note, that extraction yields higher than $35 \% \mathrm{DW}$ are quite rare in nature [21], which confirms the value of Ericaceae leaves as cost-effective sources of phenolic extracts. Furthermore, the highest 
TPC levels reported earlier for ethanol leaf extracts of Ericaceae plants did not exceed $200 \mathrm{mg}$ GAE/g DW [11] and $290 \mathrm{mg} / \mathrm{g}$ DW as expressed as catechin equivalents [9], which puts G. procumbens in a very good position comparing to other family members.

Figure 1. (a) Optimisation of the extraction process: yield and recovery of total phenolics from the leaf material dry weight; (b) Total phenolic content of dry leaf extracts (TPC).
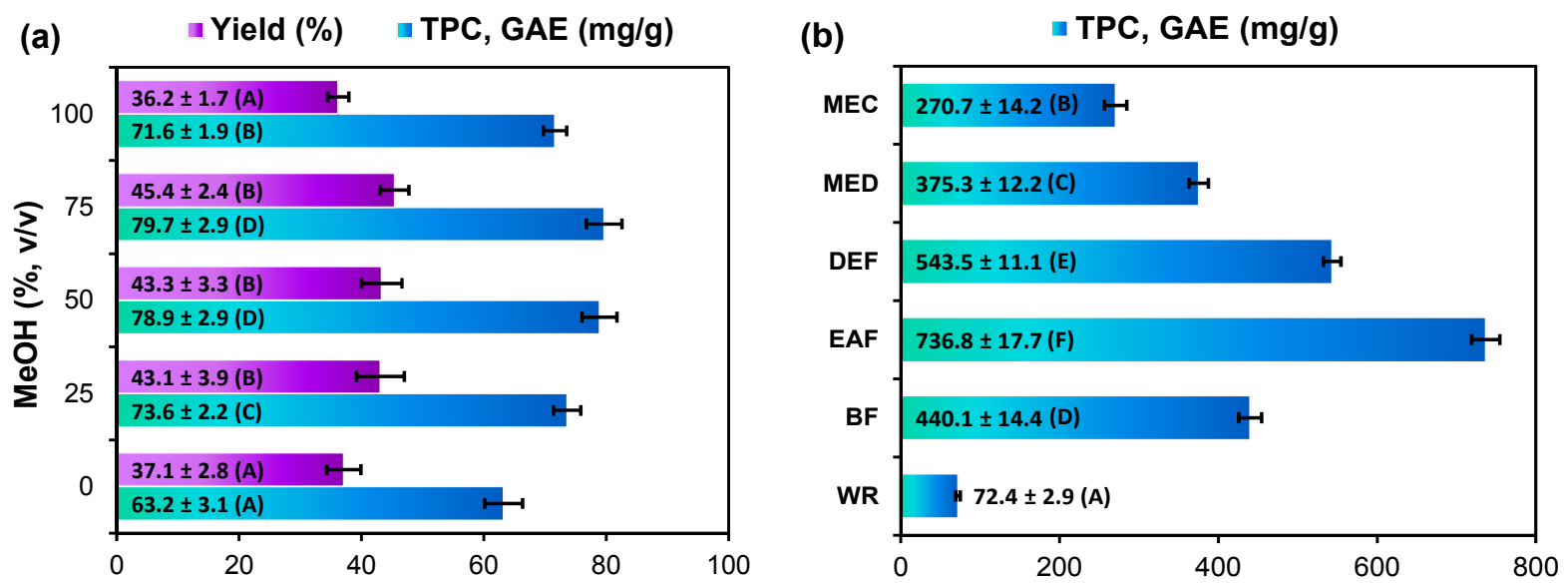

Crude leaf extracts usually contain ballast substances (lipoidal or others) that can significantly impair their physical properties, activity and phenolic levels. Due to this fact, there is general tendency in phytotherapy to replace obsolete and ineffective traditional dosage forms with preparations based on standardized dry extracts containing purified and concentrated active constituents [23]. Fractionated extraction is a good way to find solvents that are more specific, for a particular fraction, than water or alcohol and obtain extracts with enhanced activity.

To concentrate the phenolic fraction, the studied leaf material was first defatted with chloroform to obtain the chloroform extract (CHE), and then extracted with the optimized solvent to yield the purified methanol extract (MED). Finally, MED was fractionated between organic solvents to give the fractions of diethyl ether (DEF), ethyl acetate (EAF), $n$-butanol (BF), and the water residue (WR) (for scheme illustrating the extraction process see Figure S1). After removal of the ballast CHE with a significant extraction yield (7.40\% DW of the plant material) but low phenolic content (12.7 $\pm 0.3 \mathrm{mg}$ GAE/g DW), the TPC level in MED increased to $375.3 \pm 12.2 \mathrm{mg}$ GAE/g DW with only a slightly lower semi-preparative extraction yield (39.4\% DW of the plant material) than observed for MEC. The fractionation led to the further enrichment of polyphenols (Figure 1b) with the highest TPC levels found in EAF (736.8 $\pm 17.7 \mathrm{mg} \mathrm{GAE} / \mathrm{g} \mathrm{DW})$ and DEF (543.5 $\pm 11.1 \mathrm{mg} \mathrm{GAE} / \mathrm{g} \mathrm{DW})$, which puts the Gaultheria extracts among those richest in polyphenols, alongside commercial ethanol extract of grape seed (ca. $600 \mathrm{mg}$ GAE/g DW) [26] or the ethyl acetate fractions of green tea and green mate (580 mg/g GAE DW) [27].

All data expressed as mean values $\pm \mathrm{SD}(n=3)$ represented by error bars. GAE, gallic acid equivalents, calculated per dry weight of the plant material (a) or extract (b), respectively. For each parameter different capital letters indicate significant differences $(p<0.05)$. Extract codes: MEC, crude 75\% $(v / v)$ aqueous methanol extract; MED, purified (defatted) methanol extract; DEF, diethyl ether fraction; EAF, ethyl acetate fraction; $\mathrm{BF}, n$-butanol fraction; WR, water residue. 


\subsection{Antioxidant Activity of G. procumbens Dry Leaf Extracts}

Oxidative stress is the condition that occurs when the steady-state balance of pro-oxidants to antioxidants is shifted in the direction of the former, creating the potential for organic damage. Pro-oxidants are free radicals, atoms or clusters of atoms with unpaired electrons, among which ROS are prevailing $[17,18]$. A factor that provides a distinct challenge in the assay of antioxidant capacity is that within biological systems, there are multiple free radical and oxidative molecules, which need to be neutralized by different redox mechanisms. A valuable antioxidant should be thus effective against various pro-oxidants and able to react via both single electron transfer (SET) and hydrogen atom transfer (HAT) basic mechanisms [24].

According to these rules, antioxidant activity of the Gaultheria leaf extracts was studied using five complementary in vitro assays: the 2,2-diphenyl-1-picrylhydrazyl (DPPH) free radical scavenging and the ferric reducing antioxidant power (FRAP) tests - two the most frequently used SET-type methods, as well as the inhibition of linoleic acid (LA) peroxidation, the superoxide anion $\left(\mathrm{O}_{2}{ }^{\circ-}\right)$ scavenging and the hydrogen peroxide $\left(\mathrm{H}_{2} \mathrm{O}_{2}\right)$ scavenging tests - three more physiologically-relevant systems which involve the HAT mechanism [21]. Such a study design created the possibility to reflect interactions of the extracts with both nitrogen- and oxygen-centered free radicals (DPPH and $\mathrm{O}_{2}{ }^{--}$), non-radical ROS $\left(\mathrm{H}_{2} \mathrm{O}_{2}\right)$, and transition metal ions $\left(\mathrm{Fe}^{3+}\right)$, as well as to study some of these interactions in the models of lipid oxidation and enzymatic redox systems (xanthine/xanthine oxidase) [19,24].

In all applied tests, the analyzed extracts displayed a concentration-dependent activity with a wide range of final capacities depending on the extraction solvent (Table 1, Figure 2). The highest activity parameters of the extracts in comparison to phenolic standards were observed in the $\mathrm{DPPH}$ and $\mathrm{O}_{2}{ }^{-}$ scavenging tests and in the FRAP assay. In all tests EAF was the most active extract. Additionally, in the FRAP and LA-peroxidation assays no statistically significant differences were observed between antioxidant capacities of EAF and DEF (Table 1).

The scavenging activity of EAF against DPPH radical was significantly higher or not statistically different than the activity of several phenolic standards including industrial antioxidants BHA, BHT, and TBHQ (Table 1). In the $\mathrm{O}_{2}{ }^{--}$scavenging test, EAF was more active than ascorbic acid (Figure 2a), and the ability to react directly with $\mathrm{O}_{2}{ }^{--}$was confirmed for the extracts by no inhibitory effect on xanthine oxidase in the simultaneous monitoring of uric acid production. Activity parameters of the extracts in the $\mathrm{H}_{2} \mathrm{O}_{2}$ quenching test ( $\mathrm{SC}_{50}$ values, Figure $2 \mathrm{~b}$ ) were significantly worse than that of standard quercetin (QU). However, at the concentration of $20 \mu \mathrm{g} / \mathrm{mL}$ the most active EAF exhibited similar scavenging percentage (results not shown). Moreover, when comparing with other plant extracts tested in the same conditions, the title extracts exhibited significantly higher activity against both $\mathrm{O}_{2}{ }^{-}$ and $\mathrm{H}_{2} \mathrm{O}_{2}$ [28]. This activity is of great relevance for potential health benefits of eastern teaberry extracts, as both molecules are the most physiologically important ROS implicated in various oxidative stress-related pathologies including inflammatory diseases, ischemia-reperfusion injury, cancer, and the aging process [29]. 
Table 1. Comparison of antioxidant activity of G. procumbens dry leaf extracts and standard antioxidants in DPPH, FRAP and inhibition of linoleic acid peroxidation tests ${ }^{a}$.

\begin{tabular}{|c|c|c|c|}
\hline Analyte & $\begin{array}{c}\text { Radical Scavenging Activity }{ }^{b} \\
\text { DPPH }\left(\mathrm{EC}_{50}, \mu \mathrm{g} / \mathrm{mL}\right)\end{array}$ & $\begin{array}{c}\text { Reducing Power }{ }^{c} \\
\text { FRAP }\left(\mathrm{mmol} \mathrm{Fe}^{2+} / \mathrm{g}\right)\end{array}$ & $\begin{array}{c}\text { LA-Peroxidation }^{d} \\
\quad\left(\mathrm{IC}_{50}, \mu \mathrm{g} / \mathrm{mL}\right)\end{array}$ \\
\hline MEC & $8.35 \pm 0.28^{G}$ & $4.58 \pm 0.24^{B}$ & $175.98 \pm 7.78^{H}$ \\
\hline MED & $6.67 \pm 0.43^{F}$ & $5.97 \pm 0.21^{C}$ & $207.98 \pm 9.47^{I}$ \\
\hline DEF & $4.34 \pm 0.24^{E}$ & $12.50 \pm 0.84^{F}$ & $109.39 \pm 5.36^{G}$ \\
\hline EAF & $2.90 \pm 0.15^{C}$ & $12.77 \pm 0.76^{F}$ & $123.94 \pm 6.11^{G}$ \\
\hline BF & $4.94 \pm 0.25^{E}$ & $8.17 \pm 0.48^{D}$ & $164.77 \pm 5.77^{H}$ \\
\hline WR & $30.91 \pm 1.43^{H}$ & $1.46 \pm 0.08^{A}$ & $651.85 \pm 20.21^{J}$ \\
\hline $\mathbf{C A}$ & $2.17 \pm 0.11^{B}$ & $25.37 \pm 0.44^{I}$ & $69.68 \pm 0.70^{F}$ \\
\hline CHA & $4.42 \pm 0.13^{E}$ & $18.04 \pm 0.79^{H}$ & $52.47 \pm 2.03^{E}$ \\
\hline QU & $1.63 \pm 0.07^{A}$ & $36.02 \pm 1.10^{J}$ & $48.51 \pm 1.74^{D}$ \\
\hline RT & $3.44 \pm 0.09^{D}$ & $11.89 \pm 0.70^{E, F}$ & $67.73 \pm 0.34^{F}$ \\
\hline BHA & $2.90 \pm 0.14^{C}$ & $16.13 \pm 0.83^{G}$ & $14.33 \pm 0.70^{A}$ \\
\hline BHT & $6.54 \pm 0.28^{F}$ & $18.89 \pm 0.42^{H}$ & $21.58 \pm 0.95^{B}$ \\
\hline TBHQ & $2.73 \pm 0.12^{C}$ & $15.50 \pm 0.71^{G}$ & $36.53 \pm 1.04^{C}$ \\
\hline TX & $4.34 \pm 0.22^{E}$ & $10.83 \pm 0.32^{E}$ & $22.45 \pm 1.10^{B}$ \\
\hline
\end{tabular}

${ }^{a}$ Results are the mean values ( \pm SD for replicates) calculated per dry weight of the extract or standard: CA, $(+)$-catechin; CHA, 5-O-caffeoylquinic acid (chlorogenic acid); QU, quercetin; RT, rutin; BHA, butylated hydroxyanisole; BHT, 2,6-di-tert-butyl-4-methylphenol; TBHQ, tert-butylhydrochinon; TX, Trolox ${ }^{\circledR}$. For extract codes see Figure 1. Different superscripts (capitals) in each column indicate significant differences in the means at $p<0.05$. Bolded values indicate the best antioxidants among extracts; ${ }^{b}$ Radical-scavenging efficiency expressed as $\mathrm{EC}_{50}$, effective concentration, amount of antioxidant needed to decrease the initial DPPH concentration by $50 \%(n=2 \times 5 \times 1) ;{ }^{c}$ Ferric reducing antioxidant power $(n=2 \times 5 \times 1){ }^{d}$ Ability to inhibit linoleic acid (LA) peroxidation expressed as $\mathrm{IC}_{50}$, inhibition concentration, amount of antioxidant needed to decrease the LA-peroxidation by $50 \%, n=3 \times 1$.

Figure 2. Radical-scavenging activity of $G$. procumbens dry leaf extracts towards: (a) superoxide anion $\left(\mathrm{O}_{2}{ }^{--}\right)$and (b) hydrogen peroxide $\left(\mathrm{H}_{2} \mathrm{O}_{2}\right)$.

(a)

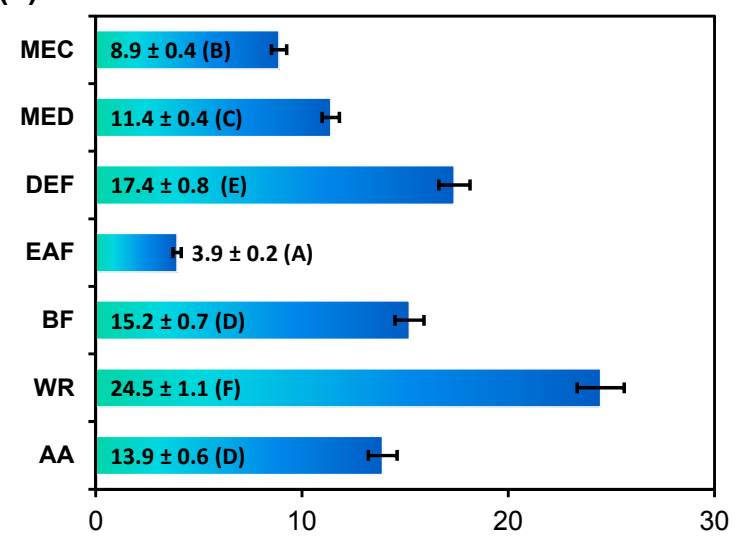

(b)

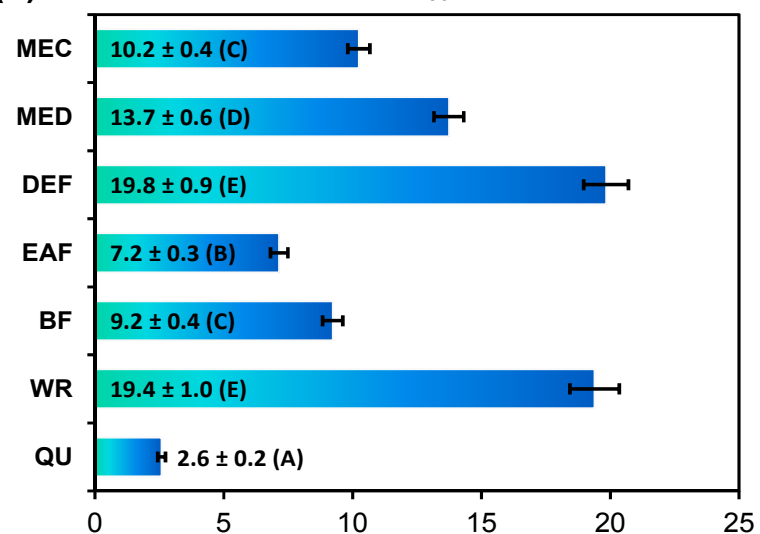

All data expressed as mean $\mathrm{SC}_{50}$ values $\pm \mathrm{SD}(n=3)$ represented by error bars. For each parameter different capital letters indicate significant differences $(p<0.05)$. Scavenging efficiencies $\left(\mathrm{SC}_{50}\right)$, amounts of antioxidants needed to decrease the initial ROS concentration by $50 \%(n=3 \times 1)$. Extract codes are given in Figure 1. Positive standards: AA, ascorbic acid; QU, quercetin. 
The FRAP activity of the most active extracts was comparable to the activity of rutin (RT) and synthetic vitamin E (Trolox, TX), but in the same time it was 1.5-3 times lower than those of the other standards (Table 1). For small molecular phenolics, such as QU and catechin (CA), their extremely high FRAP activity expressed in weight units might have been partially affected by low molecular mass and better reaction kinetics in comparison to macromolecular constituents [30], especially tannin-type proanthocyanidins abundant in Gaultheria extracts (see Sections 2.4 and 2.5). On the other hand, the slow reaction rate of plant extracts may imply an ability to retain or even increase their reducing power with time, and might thus signify a longer protecting effect against oxidative damage in vivo [30].

The chain-breaking activity studies in the LA-peroxidation assay revealed relatively the lowest capacities of the leaf extracts in comparison to other applied tests (Table 1). The most active EAF and DEF showed even up to eight times higher $\mathrm{IC}_{50}$ values than lipophilic antioxidants $\mathrm{BHA}$ and BHT used as preservatives of industrial lipoidal products. On the other hand, the polar standards, i.e., QU, RT and CA, acted only up to two times stronger than EAF and DEF, indicating that the observed activity differences between analytes may be primarily attributed to their hydrophobicity and affinity restrictions to the oxidized double bonds of LA.

Correlation studies of the antioxidant data matrix including the TPC levels (Table 2) revealed strong linear relationships $(|r| \geq 0.7)$ between most of the tested variables. Some of these trends were statistically significant at $\alpha=0.05$, with the most substantial correlations found between activity parameters from the DPPH and LA-inhibition tests, as well as between those from the scavenging tests of $\mathrm{O}_{2}{ }^{\cdot-}$ and $\mathrm{H}_{2} \mathrm{O}_{2}$. Moreover, in several cases, e.g., for the correlation between the DPPH EC 50 and FRAP values, strong effects were observed with the probability $(p)$ values within the range $0.05-0.10$. Although not allowing unambiguous confirmation of direct correspondence between these variables, the results may nevertheless indicate quite universal antioxidant character of the analyzed extracts. As the fractionation process usually results in the separation of phenolics of different structures and activities [31], the strong correlations between the results of the assays varying with regard to their basic reactions are uncommon [24]. The significant relationships found between activity parameters of the G. procumbens fractionated extracts in some of the applied test systems, especially in the DPPH, LA-peroxidation and FRAP assays, were thus of note. For further inquiry on this matter, the parallel correlation studies were run for the standards. The linear relationships between activity parameters of the standards in three above mentioned tests were significantly weaker $(|r| \leq 0.455), p \geq 0.25)$ than those observed for Gaultheria extracts. The substantially higher $|r|$-values for eastern teaberry extracts might be explained by some additive or synergistic effects of their antioxidant constituents and confirm their versatility in different redox reactions. Similar effects, often observed for plant extracts, are usually affected by complementary activity, regeneration mechanisms, and formation of stable intermolecular complexes between individual antioxidants [32].

Linear correlations between antioxidant activity parameters and TPC levels are frequently accepted as convincing evidence for determinative impact of phenolics on the tested capacity [30]. In the case of Gaultheria extracts, very strong and statistically significant effects were found in the DPPH and FRAP tests (Table 2). For other assays these trends were less evident $(|r| \geq 0.7, p>0.05)$ or negligible $(|r|<0.5, p>0.05)$, suggesting that some aspects of the tested activity could be partially related to non-phenolic compounds. In this context, it was important that strong DPPH scavenging activity was reported previously [14] for volatile lipophilic fraction (essential oil) of G. procumbens leaves 
$\left(\mathrm{EC}_{50}=30.61 \mathrm{mg} / \mathrm{mL}\right.$ versus $48.52 \mathrm{mg} / \mathrm{mL}$ for gallic acid). On the other hand, considering composition of the oil (96.9\% methyl salicylate [14]) and structure of the main component (lack of free hydroxyl groups) these results are controversial. Therefore, in the present study, we decided to verify the DPPH scavenging capacity of volatile and non-volatile lipophilic fractions of the leaves. In parallel tests, the activity of CHE $\left(\mathrm{EC}_{50}=154.2 \pm 7.7 \mu \mathrm{g} / \mathrm{mL}\right)$ and methyl salicylate (no effect up to the concentration of $0.4 \mathrm{~g} / \mathrm{mL})$ was very weak or negligible in comparison to gallic acid $(0.95 \pm 0.05 \mu \mathrm{g} / \mathrm{mL})$ and the polar extracts (Table 1), which confirmed the determinative impact of non-volatile polar compounds on the antioxidant activity of eastern teaberry leaves.

Table 2. Correlation $(r)$ coefficients and probability $(p)$ values of estimated linear relationships between antioxidant activity parameters and total phenolic contents of Gaultheria extracts ${ }^{a}$.

\begin{tabular}{|c|c|c|c|c|c|}
\hline$r(p)$ for: & DPPH EC 50 & FRAP & LA-Inh IC s0 & $\mathrm{O}_{2}^{*-} \mathrm{SC}_{50}$ & $\mathrm{H}_{2} \mathrm{O}_{2} \mathrm{SC}_{50}$ \\
\hline DPPH EC50 & - & $-0.7822(0.066)$ & $0.9919(0.000) *$ & $0.7450(0.089)$ & $0.5579(0.250)$ \\
\hline FRAP & $-0.7822(0.066)$ & - & $-0.7744(0.071)$ & $-0.4957(0.317)$ & $-0.2574(0.622)$ \\
\hline LA-Inh IC I0 & $0.9919(0.000) *$ & $-0.7744(0.071)$ & - & $0.7297(0.100)$ & $0.5185(0.292)$ \\
\hline $\mathrm{O}_{2}^{--} \mathrm{SC}_{50}$ & $0.7450(0.089)$ & $-0.4957(0.317)$ & $0.7297(0.100)$ & - & $0.8203(0.046) *$ \\
\hline $\mathrm{H}_{2} \mathrm{O}_{2} \mathrm{SC}_{50}$ & $0.5579(0.250)$ & $-0.2574(0.622)$ & $0.5185(0.292)$ & $0.8203(0.046) *$ & - \\
\hline TPC (GAE) & $-0.8255(0.043) *$ & $0.9604(0.002) *$ & $-0.7970(0.058)$ & $-0.6800(0.137)$ & $-0.4751(0.341)$ \\
\hline
\end{tabular}

${ }^{a}$ Activity parameters and total phenolic contents (TPC) were defined in Table 1 and Figures 1 and 2. Values marked with an asterisk are statistically significant at $\alpha=0.05$.

\subsection{Anti-Inflammatory Activity of G. procumbens Dry Leaf Extracts}

Inflammation is a part of the immune system's response to harmful stimuli controlled by several cellular enzymes, among which lipoxygenases and hyaluronidases play an important role. Therefore, the inhibition of both enzymes is frequently used as a criterion of anti-inflammatory potential [33].

In the present study, inhibitory effects on a model hyaluronidase and lipoxygenase were tested in vitro with dose-dependent responses observed for all analyzed leaf extracts (Figure 3). The strongest inhibitory potential towards hyaluronidase was demonstrated by EAF and BF with the inhibitory ratio of $21.83 \% \pm 0.82 \%$ and $17.93 \% \pm 0.89 \%$, respectively, at the concentration level of $100 \mu \mathrm{g} / \mathrm{mL}$ (Figure $3 \mathrm{a}$ ). At the same conditions, the inhibitory ratio for positive heparin control was $27.95 \% \pm 1.24 \%$. The other tested extracts showed weak effect on enzyme activity with the inhibitory ability less than $5 \%$.

The extracts were in general more effective inhibitors of lipoxygenase than hyaluronidase, but the activity order was similar in both assays. The highest inhibitory activity towards lipoxygenase was again observed for EAF and BF with the $\mathrm{IC}_{50}$ values of $85.41 \pm 4.13 \mu \mathrm{g} / \mathrm{mL}$ and $98.88 \pm 4.17 \mu \mathrm{g} / \mathrm{mL}$, respectively, whereas the $\mathrm{IC}_{50}$ value for positive quercetin control was $70.16 \pm 2.25 \mu \mathrm{g} / \mathrm{mL}$. The other extracts were less active (Figure $3 \mathrm{~b}$ ). At the concentration level of $100 \mu \mathrm{g} / \mathrm{mL}$, the inhibitory ratio was in the range of $14.16 \%-60.14 \%$, depending on the extract.

The measured $\mathrm{IC}_{50}$ data for lipoxygenase inhibition (LOX IC50) correlated with the DPPH EC50 values $(r=0.8957, p=0.04), \mathrm{O}_{2}{ }^{--} \mathrm{SC}_{50}(r=0.8665, p=0.06), \mathrm{H}_{2} \mathrm{O}_{2} \mathrm{SC}_{50}$ scores $(r=0.8679, p=0.06)$, and $\mathrm{IC}_{50}$ values for LA-peroxidation test $(r=0.7148, p=0.06)$, indicating that anti-inflammatory and antioxidant activity of Gaultheria extracts are closely related. The relatively high correlation between LOX IC 50 and TPC values $(r=-0.8175)$ with low statistical significance $(p=0.09)$ may suggests in 
turn that both phenolic and non-phenolic compounds are co-responsible for the anti-inflammatory activity of the extracts, but probably with the major role of polyphenols.

Figure 3. Anti-inflammatory activity of $G$. procumbens dry leaf extracts: inhibitory activity on: (a) hyaluronidase and (b) lipoxygenase.
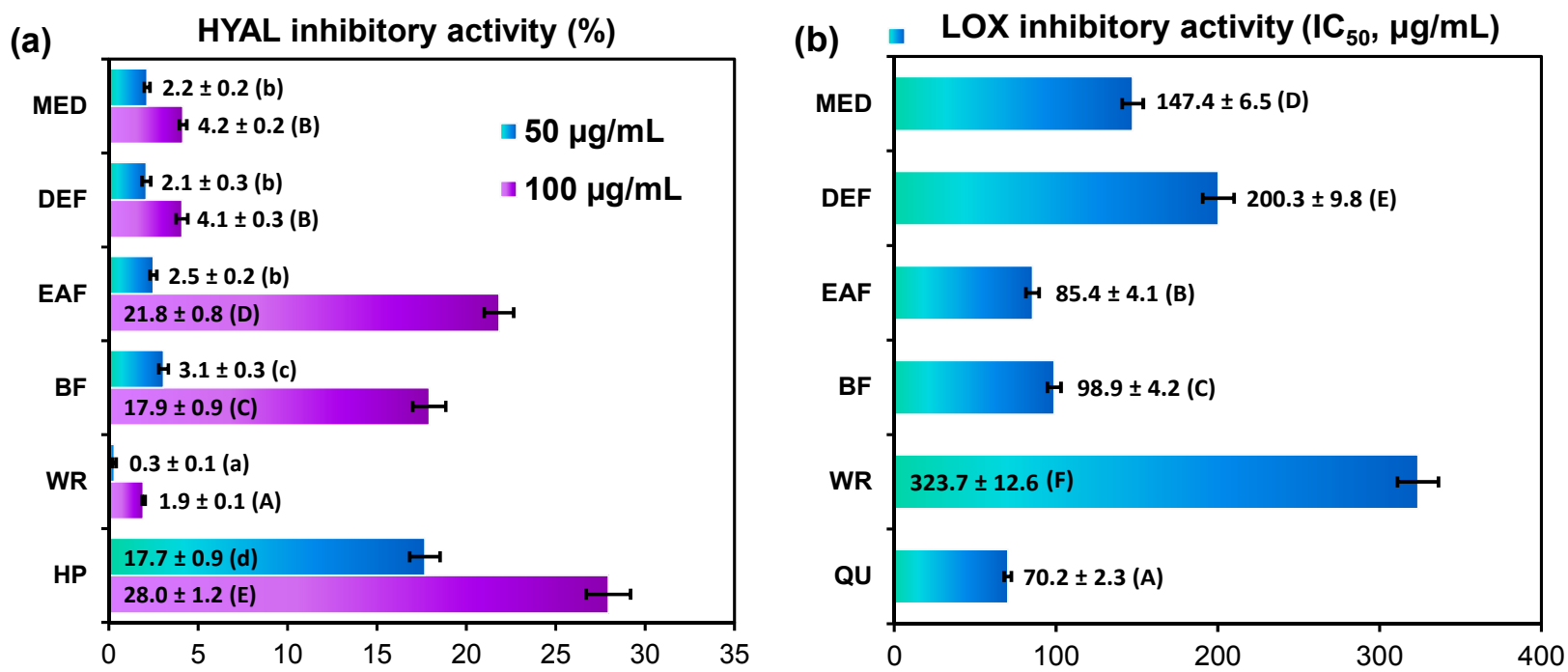

All data expressed as mean values $\pm \mathrm{SD}(n=3 \times 1)$ represented by error bars. $\mathrm{IC}_{50}, 50 \%$ inhibition of enzyme activity. For each parameter different letters in parentheses indicate significant differences $(p<0.05)$. For extract codification see Figure 1. Positive standards: HP, heparin; QU, quercetin.

\subsection{Qualitative UHPLC-PDA-ESI-MS ${ }^{3}$ Profiling of G. procumbens Leaf Phenolics}

The qualitative UHPLC-PDA-ESI-MS ${ }^{3}$ survey on the leaf extracts revealed the presence of over forty phenolic constituents (UHPLC peaks 1-44), thirty five of which were fully or tentatively identified in contrast to only nine compounds described previously [20]. The main identification data of all detected peaks and the UHPLC fingerprints of the most active extracts are presented in Table 3 and Figure 4, respectively (for full $\mathrm{MS}^{3}$ data see Table S1). According to the spectral profiles, three major groups could be distinguished among analytes including phenolic acids and related quinic acid pseudodepsides, proanthocyanidins, and flavonoids.

Table 3. Phenolic analytes detected in G. procumbens leaf extracts by UHPLC-PDA-ESI-MS 3 .

\begin{tabular}{|c|c|c|c|c|c|c|}
\hline Peak & Analyte & $\begin{array}{c}\mathbf{R}_{\mathbf{t}} \\
(\mathbf{m i n}) \\
\end{array}$ & $\begin{array}{c}\text { UV } \lambda_{\max } \\
(\mathbf{n m})\end{array}$ & $\begin{array}{c}{[\mathrm{M}-\mathrm{H}]^{-}} \\
(m / z) \\
\end{array}$ & Formula & Extract \\
\hline 1 & protocatechuic acid (PCA) ${ }^{a}$ & 4.4 & 295 & 153 & $\mathrm{C}_{7} \mathrm{H}_{6} \mathrm{O}_{4}$ & DEF \\
\hline 2 & 3-O-caffeoylquinic acid (NCHA) ${ }^{a}$ & 6.2 & 325 & 353 & $\mathrm{C}_{16} \mathrm{H}_{18} \mathrm{O}_{9}$ & all \\
\hline 3 & $p$-hydroxybenzoic acid $(p \mathrm{HBA})^{a}$ & 7.6 & 254 & 137 & $\mathrm{C}_{7} \mathrm{H}_{6} \mathrm{O}_{3}$ & DEF \\
\hline 4 & 3-O-p-coumaroylquinic acid ${ }^{a}$ & 9.3 & 310 & 337 & $\mathrm{C}_{16} \mathrm{H}_{18} \mathrm{O}_{8}$ & $\mathrm{DEF}, \mathrm{EAF}, \mathrm{BF}$ \\
\hline 5 & vanillic acid $^{a}$ & 10.3 & 260,291 & 167 & $\mathrm{C}_{8} \mathrm{H}_{8} \mathrm{O}_{4}$ & DEF \\
\hline 6 & 5-O-caffeoylquinic acid (CHA) ${ }^{a}$ & 10.7 & 325 & 353 & $\mathrm{C}_{16} \mathrm{H}_{18} \mathrm{O}_{9}$ & MED, EAF, BF, WR \\
\hline 7 & $(+)-\operatorname{catechin}(\mathrm{CA})^{a}$ & 10.9 & 280 & 289 & $\mathrm{C}_{15} \mathrm{H}_{14} \mathrm{O}_{6}$ & MED, DEF \\
\hline 8 & caffeic acid (CFA) ${ }^{a}$ & 11.7 & 325 & 179 & $\mathrm{C}_{9} \mathrm{H}_{8} \mathrm{O}_{4}$ & DEF \\
\hline 9 & 4- $O$-caffeoylquinic acid (CCHA) ${ }^{a}$ & 12.6 & 325 & 353 & $\mathrm{C}_{16} \mathrm{H}_{18} \mathrm{O}_{9}$ & all \\
\hline 10 & 3-O-feruloylquinic acid & 14.2 & 325 & 367 & $\mathrm{C}_{17} \mathrm{H}_{20} \mathrm{O}_{9}$ & EAF \\
\hline
\end{tabular}


Table 3. Cont.

\begin{tabular}{|c|c|c|c|c|c|c|}
\hline Peak & Analyte & $\begin{array}{c}\mathbf{R}_{\mathrm{t}} \\
(\mathrm{min}) \\
\end{array}$ & $\begin{array}{c}\text { UV } \lambda_{\max } \\
(\mathbf{n m})\end{array}$ & $\begin{array}{c}{[\mathbf{M}-\mathbf{H}]^{-}} \\
(m / z) \\
\end{array}$ & Formula & Extract \\
\hline 11 & procyanidin B-type dimer & 14.9 & 280 & 577 & $\mathrm{C}_{30} \mathrm{H}_{26} \mathrm{O}_{12}$ & MED, DEF, EAF, BF \\
\hline 12 & unknown compound & 15.7 & 254 & 481 & & MED, DEF, BF \\
\hline 13 & $(-)$-epicatechin $(\mathrm{ECA})^{a}$ & 16.5 & 280 & 289 & $\mathrm{C}_{15} \mathrm{H}_{14} \mathrm{O}_{6}$ & MED, DEF, EAF, BF \\
\hline 14 & 4-O-p-coumaroylquinic acid & 16.6 & 310 & 337 & $\mathrm{C}_{16} \mathrm{H}_{18} \mathrm{O}_{8}$ & $\mathrm{BF}$ \\
\hline 15 & unknown compound & 17.3 & 280 & 559 & & all \\
\hline 16 & $p$-coumaric acid $(p \mathrm{CA})^{a}$ & 19.1 & 310 & 163 & $\mathrm{C}_{9} \mathrm{H}_{8} \mathrm{O}_{3}$ & DEF \\
\hline 17 & procyanidin A-type trimer (PA) & 19.8 & 280 & 863 & $\mathrm{C}_{45} \mathrm{H}_{36} \mathrm{O}_{18}$ & MED, DEF, EAF, BF \\
\hline 18 & procyanidin B-type trimer & 20.8 & 280 & 865 & $\mathrm{C}_{45} \mathrm{H}_{38} \mathrm{O}_{18}$ & MED, EAF, BF \\
\hline 19 & procyanidin A-type dimer & 22.1 & 280 & 575 & $\mathrm{C}_{30} \mathrm{H}_{24} \mathrm{O}_{12}$ & MED, EAF, BF \\
\hline 20 & unknown compound & 22.2 & 267,298 & 639 & & DEF \\
\hline 21 & caffeoylquinic acid derivative & 22.4 & 325 & 391 & & MED, EAF \\
\hline 22 & unknown compound & 24.3 & 280 & 473 & & DEF, EAF \\
\hline 23 & quercetin pentoside-glucuronide & 24.9 & 257,356 & 609 & $\mathrm{C}_{26} \mathrm{H}_{26} \mathrm{O}_{17}$ & MED, DEF, BF, WR \\
\hline 24 & procyanidin A-type trimer & 25.1 & 280 & 863 & $\mathrm{C}_{45} \mathrm{H}_{36} \mathrm{O}_{18}$ & EAF \\
\hline 25 & unknown compound & 26.3 & 280 & 451 & & DEF, EAF \\
\hline 26 & quercetin 3-O-galactoside ( $\mathrm{HY})^{a}$ & 27.2 & 254,353 & 463 & $\mathrm{C}_{21} \mathrm{H}_{20} \mathrm{O}_{12}$ & MED, DEF, EAF, BF \\
\hline 27 & quercetin 3-O-glucoside ( IQ) ${ }^{a}$ & 28.1 & 256,353 & 463 & $\mathrm{C}_{21} \mathrm{H}_{20} \mathrm{O}_{12}$ & all \\
\hline 28 & quercetin 3-O-glucuronide ( MQ) ${ }^{a}$ & 28.8 & 256,356 & 477 & $\mathrm{C}_{21} \mathrm{H}_{18} \mathrm{O}_{13}$ & all \\
\hline 29 & quercetin 3-O-arabinoside $(\mathrm{GV})^{a}$ & 30.3 & 258,356 & 433 & $\mathrm{C}_{20} \mathrm{H}_{18} \mathrm{O}_{11}$ & MED, DEF, EAF, BF \\
\hline 30 & quercetin derivative & 30.6 & 258,354 & 333 & & DEF \\
\hline 31 & kaempferol 3-O-glucuronide & 33.0 & 265,349 & 461 & $\mathrm{C}_{21} \mathrm{H}_{18} \mathrm{O}_{12}$ & all \\
\hline 32 & quercetin 3-O-glucuronide methyl ester & 33.9 & 265,356 & 491 & $\mathrm{C}_{22} \mathrm{H}_{20} \mathrm{O}_{13}$ & MED, DEF, EAF, BF \\
\hline 33 & kaempferol 3-O-glucuronide methyl ester & 38.8 & 265,348 & 475 & $\mathrm{C}_{22} \mathrm{H}_{20} \mathrm{O}_{12}$ & EAF \\
\hline 34 & unknown compound & 39.0 & 286,326 & 409 & & $\mathrm{BF}$ \\
\hline 35 & kaempferol 3-O-glucoside ( $\mathrm{AG})^{a}$ & 39.9 & 265,345 & 447 & $\mathrm{C}_{21} \mathrm{H}_{20} \mathrm{O}_{11}$ & EAF \\
\hline 36 & unknown compound & 40.3 & 280 & 451 & & DEF, EAF \\
\hline 37 & 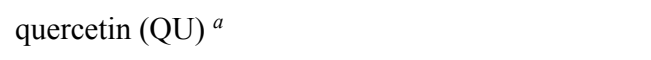 & 43.3 & 255,364 & 301 & $\mathrm{C}_{15} \mathrm{H}_{10} \mathrm{O}_{7}$ & $\mathrm{DEF}, \mathrm{EAF}$ \\
\hline 38 & unknown compound & 43.7 & 286,326 & 409 & & $\mathrm{BF}$ \\
\hline 39 & unknown compound & 44.4 & 280 & 435 & & DEF \\
\hline 40 & quercetin 3-O-pentoside-glucuronide butyl ester & 4.4 & 295 & 153 & $\mathrm{C}_{30} \mathrm{H}_{34} \mathrm{O}_{17}$ & $\mathrm{BF}$ \\
\hline 41 & quercetin 3-O-glucuronide butyl ester & 6.2 & 325 & 353 & $\mathrm{C}_{25} \mathrm{H}_{26} \mathrm{O}_{13}$ & $\mathrm{BF}$ \\
\hline 42 & kaempferol 3-O-pentoside-glucuronide butyl ester & 7.6 & 254 & 137 & $\mathrm{C}_{30} \mathrm{H}_{34} \mathrm{O}_{16}$ & $\mathrm{BF}$ \\
\hline 43 & kaempferol (KA) $^{a}$ & 9.3 & 310 & 337 & $\mathrm{C}_{15} \mathrm{H}_{10} \mathrm{O}_{6}$ & $\mathrm{DEF}$ \\
\hline 44 & kaempferol 3-O-glucuronide butyl ester & 10.3 & 260,291 & 167 & $\mathrm{C}_{25} \mathrm{H}_{26} \mathrm{O}_{12}$ & $\mathrm{BF}$ \\
\hline
\end{tabular}

${ }^{a}$ Identified with authentic standards. $\mathrm{R}_{\mathrm{t}}$, retention times. UV $\lambda_{\max }$, absorbance maxima in PDA spectra. $[\mathrm{M}-\mathrm{H}]^{-}$, pseudomolecular ions in MS spectra recorded in a negative mode. For systematic names of flavonoid standards see Section 3.1. For extract codes see Figure 1. 
Figure 4. Representative UHPLC-UV chromatograms of diethyl ether (DEF) and ethyl acetate (EAF) extracts. Peak numbers refer to those implemented in Table 3.

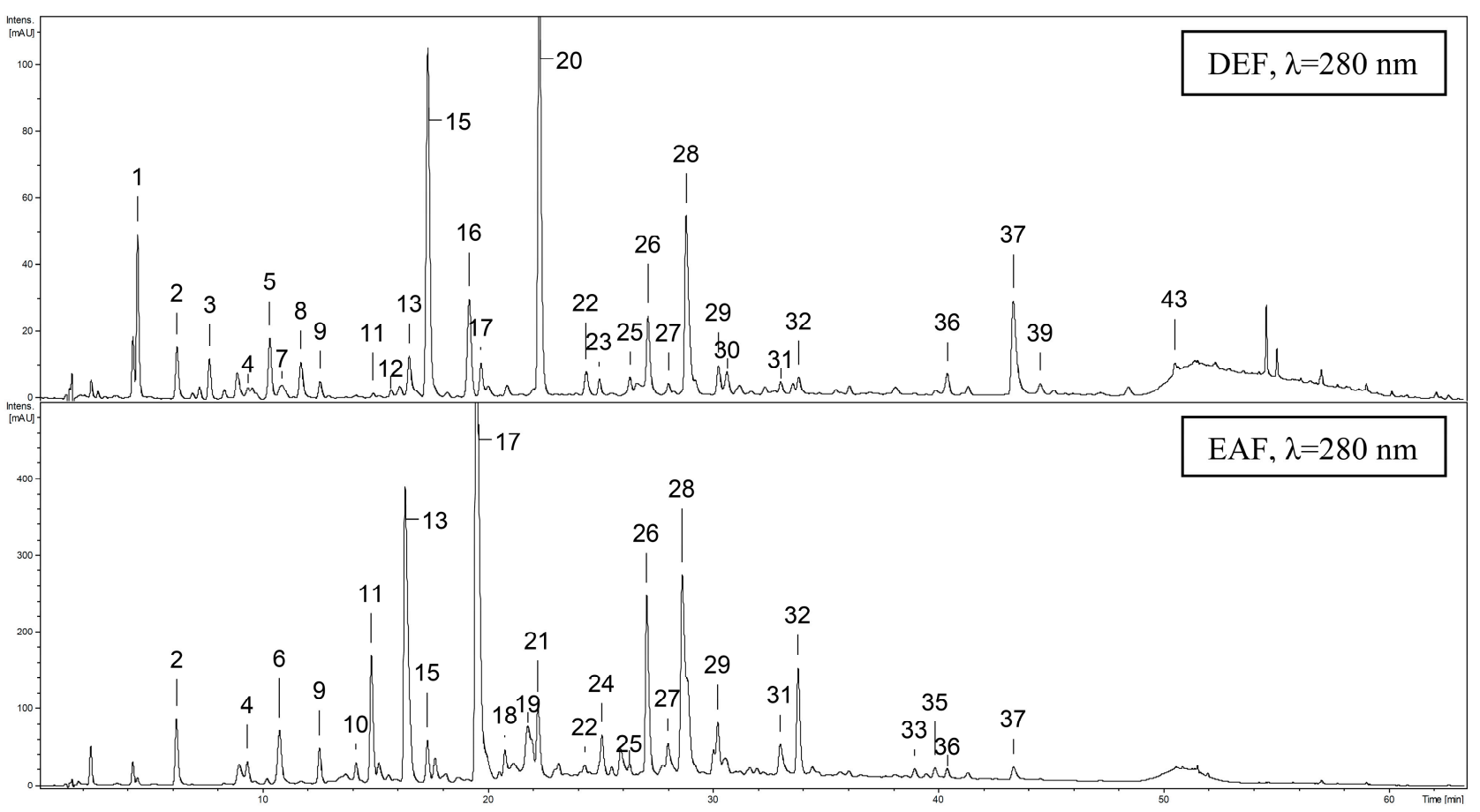

\subsubsection{Phenolic Acids and Related Phenolic Compounds}

The MS/MS profiles of quinic acid monoesters are well studied and the locations of cinnamoyl groups in a pseudodepside structure can be easily determined based on the relative intensities of diagnostic $\mathrm{MS}^{n}$ ions [34]. Among this group, compounds 2, 6 and 9 (with the same UV maxima at $325 \mathrm{~nm}$ ) giving parent $[\mathrm{M}-\mathrm{H}]^{-}$ions at $\mathrm{m} / \mathrm{z} 353$ were detected in all extracts. The $\mathrm{MS}^{2}$ spectra of $\mathbf{2}$ and $\mathbf{6}$ showed fragment ions at $\mathrm{m} / \mathrm{z} 191$ as base peaks and an intense ( $>40 \%$ of base peak intensity) or weak ( $<5 \%$ of base peak) secondary ions at $m / z 179$, respectively. Compound 9 exhibited distinctive $\mathrm{MS}^{2}$ behavior with a dehydrated base peak at $m / z$ 173. Based on hierarchical discrimination key [34] and spiking experiments using standards, both commercial and prepared in our laboratory [35], compounds 2, 6, and 9 were characterized as 3-, 5- and 4- $O$-caffeoylquinic acids, respectively. In the case of compound 21, fragmentation of a pseudomolecular ion at $\mathrm{m} / \mathrm{z} 391$ gave fragment ion at $\mathrm{m} / \mathrm{z} 179$ as a secondary peak in $\mathrm{MS}^{2}$ spectrum, which represents typical caffeic acid-derived ion [34], observed for compounds $\mathbf{2}$ and $\mathbf{6}$. Therefore, compound $\mathbf{2 1}$ was identified tentatively as a caffeoylquinic acid derivative.

Three quinic acid derivatives containing $p$-coumaroyl and feruloyl rests in their structures were also found. Compounds 4 and 14 showed $[\mathrm{M}-\mathrm{H}]^{-}$ions at $m / z 337$ and the $\mathrm{MS}^{2}$ base fragmentation peaks derived from the cinnamic acid moiety at $\mathrm{m} / \mathrm{z} 163$ and $\mathrm{m} / \mathrm{z}$ 173, which led to the identification of 3- and 4-O-p-coumaroylquinic acids, respectively. Compound 10 displayed a $[\mathrm{M}-\mathrm{H}]^{-}$ion at $\mathrm{m} / \mathrm{z} 367$ and a $\mathrm{MS}^{2}$ base fragment ion at $m / z$ 193, which allowed identification of 3-O-feruloylquinic acid [34].

Simple derivatives of benzoic (1, 3 and 5) and cinnamic acids (8 and 16) were detected in DEF only and identified by direct comparison with reference standards and literature data [36] as protocatechuic, $p$-hydroxybenzoic, vanillic, caffeic and $p$-coumaric acids, respectively. 


\subsubsection{Flavan-3-ols (Catechins and Proanthocyanidins)}

Peaks 7, 11, 13, 17-19, and 24 (with UV maxima at $280 \mathrm{~nm}$ ) were classified as mono- to oligomeric procyanidins. Compounds 7 and 13 showed $[\mathrm{M}-\mathrm{H}]^{-}$ions at $m / z 289$ and $\mathrm{MS}^{2}$ ions at $m / z 245$ and $m / z$ 205, respectively. Standard spiking experiments and literature data [37] led to the identification of $(+)$-catechin (CA) and (-)-epicatechin (ECA). Compound 11 with a parent ion $[\mathrm{M}-\mathrm{H}]^{-}$at $\mathrm{m} / \mathrm{z} 577$, yielding $\mathrm{MS}^{2}$ diagnostic fragments at $\mathrm{m} / \mathrm{z} 451,425,407$ and 289, and compound 19 with a [M-H] $]^{-}$ signal at $\mathrm{m} / \mathrm{z} 575$ and $\mathrm{MS}^{2}$ fragment ions at $\mathrm{m} / \mathrm{z} 499,423$ and 289 were identified as procyanidin B- and A-type dimers, respectively. According to [20], these are probably procyanidins B2 and A2. Pseudomolecular ions $[\mathrm{M}-\mathrm{H}]^{-}$at $m / z 863$ with the relevant $\mathrm{MS}^{2}$ fragmentation indicated the presence of procyanidin A-type trimers $(\mathbf{1 7}, \mathbf{2 4})$, whereas a parent $[\mathrm{M}-\mathrm{H}]^{-}$ion at $\mathrm{m} / z 865$ with base daughter $\mathrm{MS}^{2}$ peaks at $\mathrm{m} / z 713$ and $\mathrm{m} / z 577$ allowed identification of a procyanidin B-type trimer (18) [37]. In the group of proanthocyanidins, 12 individuals were found, with the dominant ECA (13) and the A-type procyanidin trimer (17).

\subsubsection{Flavonoids}

Peaks 23, 26-33, 35, 37 and 40-44 with two UV maxima at approximately 250-267 and 355-365 nm were classified as flavonoids. Compounds $\mathbf{3 7}$ and $\mathbf{4 3}$ were identified with standards as free aglycones quercetin (QU) and kaempferol (KA), respectively. Glycosides were found by detection of neutral losses typical for sugar moieties (162 for hexoses, 132 for pentoses, and 176 for hexuronic acids). In the case in which one of the neutral loss masses was found, $\mathrm{MS}^{3}$ fragmentation was performed to identify the aglycone moiety [38]. Peaks 26-29 with the fragment ion in $\mathrm{MS}^{2}$ spectra at $\mathrm{m} / z 301$ (typical for QU) were identified with authentic standards as hyperoside (26, HY), isoquercitrin (27, IQ), miquelianin (28, MQ), and guajiverin (29). Due to the corresponding MS/MS profile, compound 30 was identified tentatively as a quercetin derivative. Similarly, peaks $\mathbf{3 1}$ and $\mathbf{3 5}$ with the $\mathrm{MS}^{2}$ fragment ions at $\mathrm{m} / \mathrm{z} 285$ (typical for KA) were classified as kaempferol 3-O-glucuronide and astragalin (AG), respectively. In the case of peak 23, a flavonoid diglycoside, the MS spectra in a positive mode revealed the neutral losses characteristic for a pentose (-132 amu), cleavage of glucuronic acid (-176 amu) and the aglycone signal at $\mathrm{m} / \mathrm{z}$ 303. Based on $\mathrm{MS}^{2}$ and $\mathrm{MS}^{3}$ fragmentation patterns and the published data [39], 23 was identified as a quercetin pentoside-glucuronide. Peaks 32, 41 and $\mathbf{4 0}$ gave the parent ions $[\mathrm{M}-\mathrm{H}]^{-}$at $m / z 491,533$ and 665 , respectively. Their MS spectra in a negative mode revealed the cleavage of glucuronic acid $(-176 \mathrm{amu})$ and the aglycone signal at $\mathrm{m} / \mathrm{z} 301$. Furthermore, the neutral losses distinctive for methyl group ( $-14 \mathrm{amu}$ ), butyl group ( $-56 \mathrm{amu}$ ), and butyl group with pentose $(-132 \mathrm{amu})$ were observed for compounds 32, 41 and 40, respectively. On that basis [40], they were identified as quercetin 3-O-glucuronide methyl ester, quercetin 3-O-glucuronide butyl ester and quercetin 3-O-pentoside-glucuronide butyl ester. Compounds $33\left([\mathrm{M}-\mathrm{H}]^{-}\right.$at $\left.m / z 475\right), 44\left([\mathrm{M}-\mathrm{H}]^{-}\right.$at $m / z 517)$ and $42\left([\mathrm{M}-\mathrm{H}]^{-}\right.$at $m / z$ 649) exhibited parallel fragmentation patterns as the latter ones and were recognized as analogous kaempferol derivatives. It is of note that the butyl esters $\mathbf{4 0 - 4 2}$ and 44 were observed exclusively in BF obtained after sequential liquid-liquid extraction of MED. Their absence in the mother extract suggested that they were artifacts formed during extraction. Similar conclusion could be made for methyl esters (compounds 32 and 33) per analogy. 
The study proved the presence of 16 flavonoids, among which compounds 26-28, 31, 35, 37, and $\mathbf{4 3}$ had already been reported in the genus Gaultheria [20,41], whereas compounds 23, 29, 30, 32, 33, 40-42 and 44 were detected for the first time. In all extracts flavonoids were mainly represented by three quercetin derivatives MQ (28), HY (26) and quercetin pentoside-glucuronide (23). The previously published data [20] suggested that IQ (27) is the dominant G. procumbens leaf flavonoid. However, the strong elution gradient applied by Saleem et al. [20] resulted probably in co-elution of the critical bands of IQ and MQ. The co-elution tendency was observed also by our team, especially when the strong gradient profile was used, similar to that applied in [20]. Optimization of the more selective elution profile for UHPLC-PDA-ESI-MS ${ }^{3}$-fingerprinting resulted in high resolution between the adjacent bands (Figure 4) and enabled undoubted identification of MQ as the dominant flavonoid of the title plant.

\subsection{Quantitative Profiling of G. procumbens Leaf Phenolics}

Quantitative phenolic profile was studied by UV-spectrophotometric (total proanthocyanidins) and HPLC-PDA methods (total flavonoids and fingerprinting of individual compounds). The subsequent correlation studies were applied to select the main determinants of the tested bioactivities.

As reported in Figure 5, the highest total level of individual phenolics, as assayed by HPLC-PDA (511.0 $\mathrm{mg} / \mathrm{g} \mathrm{DW}$ ), was found for EAF, which confirmed that ethyl acetate has the best ability to concentrate the bioactive constituents of $G$. procumbens leaves.

The total content of proanthocyanidins (TPA), as determined by the butanol- $\mathrm{HCl}$ assay and expressed in cyanidin chloride equivalents (CyE), was in the range of $49.6-483.4 \mathrm{mg} / \mathrm{g} \mathrm{DW}$ and constituted $65.6 \%-100.4 \%$ of the TPC values with one outlier for DEF $(21.3 \%)$, and thus prevailed strongly in the phenolic fractions of most extracts. However, this assay is not diagnostic for the degree of polymerization, and can give positive responses for molecules varying from monomers to highly condensed ones. On the other hand, RP-HPLC method enables separation of low- and medium-molecular-weight proanthocyanidins (monomers, dimers, and trimers), that are of special interest as health-promoting agents due to their beneficial profile of bioavailability and bioactivity, including antioxidant and anti-inflammatory actions [42]. All 12 individual compounds of this type identified by UHPLC-PDA-ESI-MS ${ }^{3}$ (see Section 2.4), were detectable also by HPLC-PDA, including CA, ECA and the procyanidin A-type trimer (17), marked PA. The total content of these compounds (TLPA), calculated as ECA, varied among extracts, with the highest level found for EAF (415.7 mg/g DW). The TLPA levels constituted $10.6 \%-100.4 \%$ of the TPA contents, with the highest shares observed for DEF (100.4\%) and EAF (86.5\%). As described above (Sections 2.1 and 2.2), DEF and EAF exhibited the highest TPC levels and the most potent activity in the majority of test systems. This close relationship was confirmed by a significant correlation between TLPA and TPC levels $(r=0.8675$, $p<0.05$ ) indicating a strong impact of TLPA on the FC-response. Similar trends were observed between TLPA levels and parameters of the DPPH $(r=-0.9714, p<0.01)$, inhibition of LA-peroxidation $(r=-0.9698, p<0.01)$, and lipoxygenase inhibition $(r=-0.9167, p=0.08)$ tests for most extracts except EAF, which deviated from these models by extremely high TLPA level in comparison to the exerted activity. This discrepancy could be probably connected with the flavan-3-ol profile of EAF (i.e., monomers-to-oligomers ratio) and specific reactivity of individual molecules in particular tests [43]. 
The major A-type proanthocyanidin of G. procumbens (PA) was present in considerable amounts $(5.3-136.9 \mathrm{mg} / \mathrm{g}$ DW) and ratios to the TLPA levels $(32.9 \%-100 \%)$ in all extracts except DEF (Figure 5a). Excluding this extract, a strong and statistically significant $(p<0.05)$ correlations were found between PA and FRAP levels $(r=0.9604), \mathrm{H}_{2} \mathrm{O}_{2} \mathrm{SC}_{50}(r=-0.9013)$ and $\mathrm{O}_{2}{ }^{-} \mathrm{SC}_{50}$ values $(r=-0.8216)$. Although weaker trends $(p>0.05)$ were observed for PA levels and DPPH EC 50 $(r=-0.7447), \mathrm{IC}_{50}$ for LA-peroxidation $(r=-0.7373)$, and LOX IC $\mathrm{I}_{50}$ values $(r=-0.8151)$, they cannot be discriminated, and PA could be indicated as an important determinant of the tested activities.

Figure 5. Quantitative data of G. procumbens dry leaf extracts: (a) proanthocyanidins; (b) phenolic acids; (c) flavonoid aglycones after acid hydrolysis; and (d) native flavonoids.

(a)

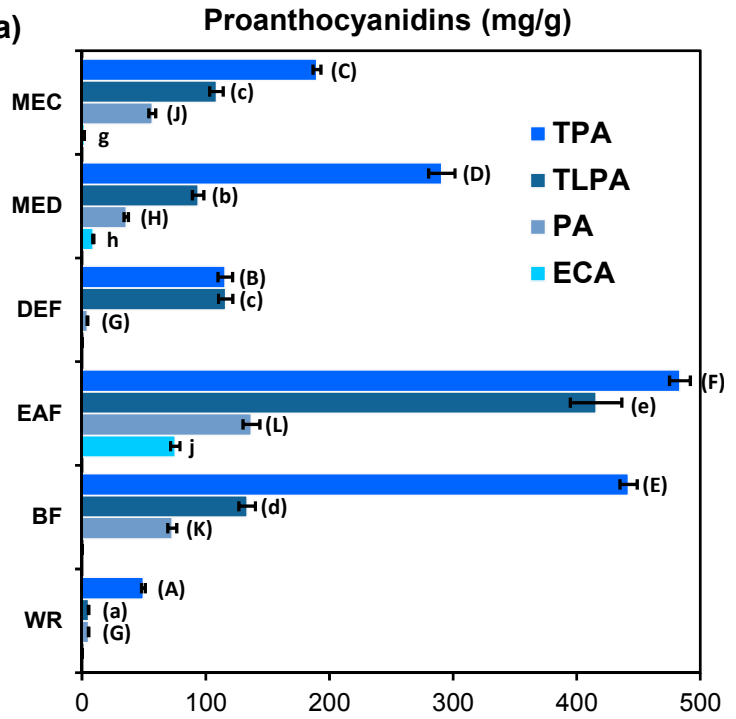

(c)

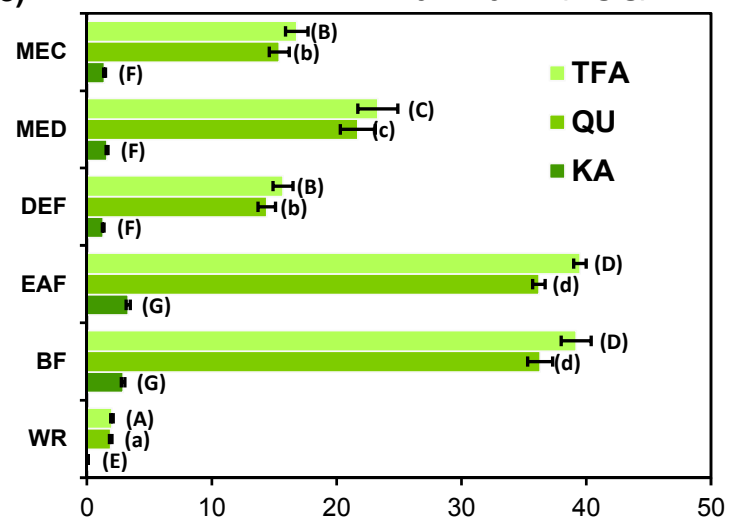

(b)

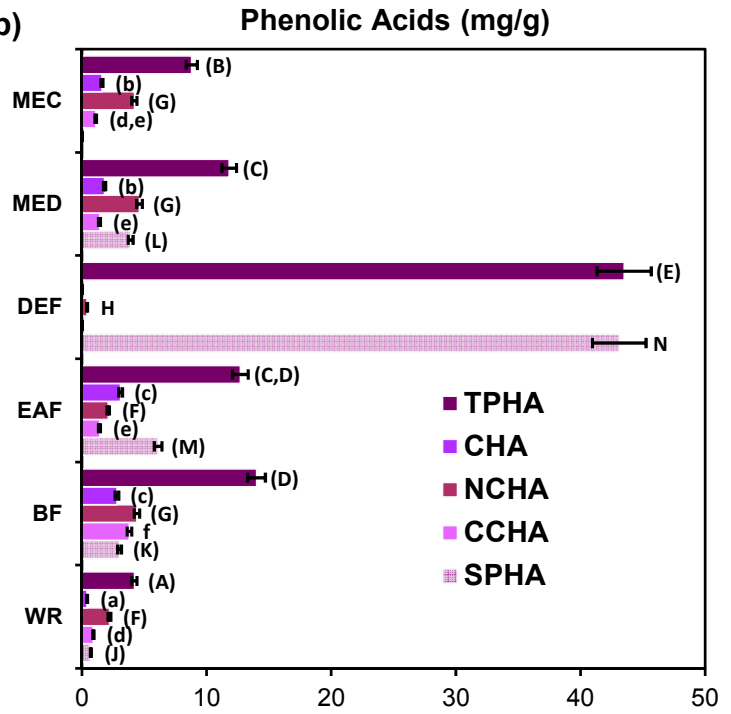

(d)

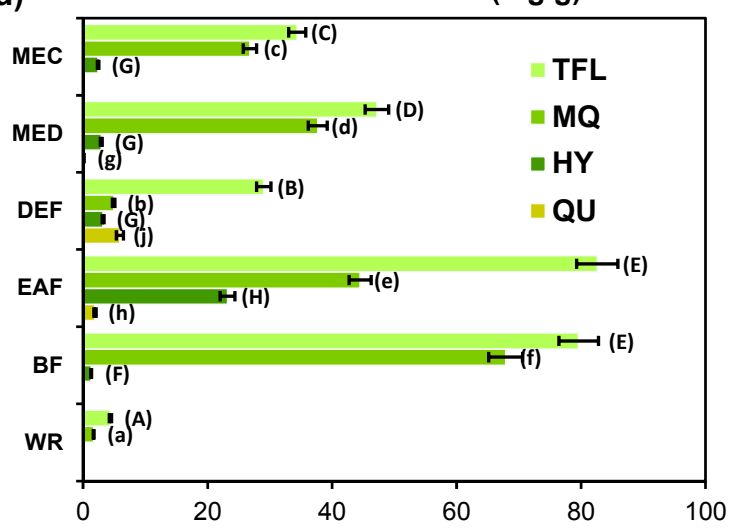

All data expressed as mean values calculated per dry weight of the extracts $\pm \operatorname{SD}(n=3 \times 3 \times 1)$ represented by error bars. For each parameter different letters in parentheses indicate significant differences $(p<0.05)$. Abbreviations: TPA, total proanthocyanidin content expressed in cyanidin chloride equivalents; TLPA, total content of individual proanthocyanidins expressed in epicatechin equivalents; ECA, (-)-epicatechin; PA, procyanidin A-type trimer; TPHA, total content of phenolic acids; CHA, 5-O-caffeoylquinic acid; NCHA, 3-O-caffeoylquinic acid; CCHA, 4-O-caffeoylquinic acid; SPHA, total content of simple hydroxybenzoic and hydroxycinnamic acids; TFA, total flavonoid content as the sum of aglycones after acid hydrolysis; TFL, total content of individual native flavonoids; QU, quercetin; KA, kaempferol; HY, hyperoside; MQ, miquelianin. All levels found by HPLC-PDA-fingerprints except for the TPA contents assayed by spectrophotometry. For extract codes see Figure 1. 
The total content of native flavonoids (TFL, Figure 5d) was quite high in all extracts (29.0-82.6 mg/g DW) except WR (4.4 mg/g DW). Two flavonol aglycones (QU and KA) were found in the extracts after acid hydrolysis, with QU constituting $91.7 \%-94.1 \%$ of the total aglycones (Figure $5 \mathrm{c}$ ). In the native extracts, free aglycones were minor or trace components $(0.1-1.9 \mathrm{mg} / \mathrm{g} \mathrm{DW})$ except for QU in DEF (5.9 mg/g DW). Among flavonoids, quercetin glycosides (mainly MQ and HY) were the most abundant. Correlation studies revealed determinative impact of flavonoids on $\mathrm{H}_{2} \mathrm{O}_{2}$ scavenging activity due to the observed significant $(p<0.05)$ relationships between both TFL and MQ levels and $\mathrm{H}_{2} \mathrm{O}_{2}$ SC50 values $(r=-0.8466$ and $r=-0.8426$, respectively). For other antioxidant activity parameters the correlations were weaker with the lowest found for the FRAP levels $(r=0.6066$ and $r=0.2570$, respectively). Lack of statistical significance of these trends at $\alpha=0.05$ suggested that the impact of flavonoids on the antioxidant capacity of Gaultheria extracts is more additive than determinative. On the other hand, significant linear relationships between the LOX IC 50 values and TFL levels $(r=-0.9651, p<0.01)$ suggested, that flavonoids are mainly responsible for enzyme mediated anti-inflammatory activity of the extracts. Although weaker than the total flavonoid effect, the impact of MQ on this activity $(r=-0.8535, p=0.07)$ is also of note. It is worth pointing out that MQ was proved to have strong in vivo antioxidant and anti-inflammatory effects [44]. The presence of MQ at high levels (26.8-37.7 mg/g DW in MEC and MED) could thus partially explain the wide biological activity of the analyzed plant.

As shown in Figure 5b, with total levels of 4.2-13.9 mg/g DW, phenolic acids are minor components of most Gaultheria extracts except DEF (43.5 mg/g DW; $23.1 \%$ of total phenolics detected by HPLC). The most abundant compounds among them were caffeoylquinic acid isomers $(3.5-11.0 \mathrm{mg} / \mathrm{g} \mathrm{DW})$ constituting $52.4 \%-83.1 \%$ of total acids. One exception to this trend was DEF, which accumulated high quantities of simple hydroxybenzoic $(29.3 \mathrm{mg} / \mathrm{g} \mathrm{DW})$ and hydroxycinnamic $(13.8 \mathrm{mg} / \mathrm{g} \mathrm{DW})$ acids. Due to its unique profile, DEF was excluded from correlation studies, which then revealed strong and significant $(p<0.05)$ linear relationships between the total contents of phenolic acids and LOX IC 50 values $(r=-0.9821)$, DPPH EC 50 values $(r=-0.9261)$, as well as $\mathrm{IC}_{50}$ values from the LA-peroxidation test $(r=-0.8850)$, and FRAP values $(r=0.8157)$. Although these relationships were less evident for $\mathrm{H}_{2} \mathrm{O}_{2}$ and $\mathrm{O}_{2}{ }^{--} \mathrm{SC}_{50}$ values $(|r| \geq 0.65, p>0.05)$, the study indicated that, despite the lower content, phenolic acids are key determinants of the tested activities.

\section{Experimental Section}

\subsection{General}

HPLC grade reagents and standards, such as bovine testis hyaluronidase; bovine serum albumin; luminal; nitrobluetetrazolium; xanthine; xanthine oxidase; hydrogen peroxide; horseradish peroxidase; lipoxygenase from soybean; 2,2-diphenyl-1-picrylhydrazyl (DPPH); 2,2'-azobis-(2-amidinopropane) dihydrochloride (AAPH); 2,4,6-tris-(2-pyridyl)-s-triazine (TPTZ); ( \pm )-6-hydroxy-2,2,7,8-tetramethylchroman-2-carboxylic acid (Trolox $\left.{ }^{\circledR}, \mathrm{TX}\right)$; caffeic acid (CFA); gallic acid monohydrate (GA); chlorogenic acid hemihydrate (CHA); $p$-coumaric acid $(p \mathrm{CA})$; protocatechuic acid $(\mathrm{PCA})$; $(+)$-catechin (CA); (-)-epicatechin (ECA); kaempferol (KA); quercetin trihydrate (QU); rutin trihydrate (RT); miquelianin (MQ, quercetin 3-O- $\beta$-D-glucuronopyranoside); astragalin (AG, kaempferol 3-O- $\beta$-D- 
glucopyranoside); isoquercitrin (IQ, quercetin 3-O- $\beta$-D-glucopyranoside); hyperoside (HY, quercetin 3- $O$ - $\beta$-D-galactopyranoside); linoleic acid (LA); and ascorbic acid (AA) were purchased from Sigma-Aldrich (Seelze, Germany/St. Louis, MO, USA), as were analytical grade $p$-hydroxybenzoic acid ( $p \mathrm{HBA}$ ); butylated hydroxyanisole (BHA); 2,6-di-tert-butyl-4-methylphenol (BHT); and tert-butylhydroquinone (TBHQ). Hyaluronic acid and heparin sodium were purchased from Fluka (Steinheim, Germany) and WZF Polfa (Warsaw, Poland). An HPLC grade (min. 96.5\% purity) guajiverin (GV, quercetin 3-O- $\alpha$-L-arabinopyranoside) standard was isolated earlier [45]. The qualitative standards of 3-O-caffeoylquinic acid (NCHA) and 4-O-caffeoylquinic acid (CCHA) were prepared by isomerization of CHA according to the known method [35]. HPLC grade solvents (acetonitrile and methanol) used for UHPLC and HPLC analyses were obtained from POCh (Gliwice, Poland). Phosphate buffered saline (PBS) was purchased from Biomed (Lublin, Poland). All other chemicals and solvents were of analytical grade and obtained from POCh (Poland). In all analyses redistilled water was used. For nonenzymatic spectrophotometric tests samples were incubated in a constant temperature using a BD 23 incubator (Binder, Tuttlingen, Germany) and measured using a Lambda 25 spectrophotometer (Perkin-Elmer, Waltham, MA, USA), in $10 \mathrm{~mm}$ quartz cuvettes. Enzymatic tests were done using 96-well plates and monitored using a microplate reader, Synergy 4 (BioTek, Winooski, VT, USA).

\subsection{Plant Material and Preparation of Dry Extracts}

Leaves of Gaultheria procumbens L. were collected in October 2012 in the nursery-garden of Ericaceae plants, Gospodarstwo Szkolkarskie Jan Cieplucha $\left(51^{\circ} 44^{\prime} \mathrm{N}, 19^{\circ} 18^{\prime} \mathrm{E}\right)$, Konstantynow Lodzki, Poland. The seeds for the nursery were imported from the William J. Beal Botanical Garden (Michigan State University, East Lansing, MI, USA), and authenticated in the Arboretum, Forestry Experimental Station of Warsaw University of Life Sciences (SGGW) in Rogow, Poland. The voucher specimen was deposited in the herbarium of the Department of Pharmacognosy, Medical University of Lodz, Poland with the number KFG/HB/12005-GPRO.

The raw material was air-dried under normal conditions, powdered with an electric grinder, and sieved through a $0.315-\mathrm{mm}$ sieve. Two portions (100 g each) were sampled, and one of them was extracted with chloroform $(1 \mathrm{~L}, 48 \mathrm{~h}$ ) in a Soxhlet apparatus to obtain the chloroform extract (CHE, $7.4 \mathrm{~g} \mathrm{DW})$. Both samples were next separately refluxed triply with $75 \%(v / v)$ aqueous methanol $(1 \mathrm{~L}$, $8 \mathrm{~h}$ ) to give the crude methanol extract (MEC, $42.5 \mathrm{~g} \mathrm{DW})$ and the defatted methanol extract (MED, $39.4 \mathrm{~g} \mathrm{DW})$, respectively. The MED (35.0 g) was suspended in water (1 L) and subjected to sequential liquid-liquid extraction with organic solvents $(8 \times 100 \mathrm{~mL}$ each) to yield diethyl ether fraction (DEF, $0.7 \mathrm{~g} \mathrm{DW}$ ), ethyl acetate fraction (EAF, $2.5 \mathrm{~g} \mathrm{DW}), n$-butanol fraction (BF, $11.9 \mathrm{~g} \mathrm{DW}$ ) and water residue (WR, $16.3 \mathrm{~g} \mathrm{DW}$ ). The organic solvent extracts were evaporated in vacuo, and the water containing fractions were lyophilized using an Alpha 1-2/LD Plus freeze dryer (Christ, Osterode am Harz, Germany) before weigh in. The extraction process was illustrated in Figure S1.

\subsection{Determination of Total Phenolic Content (TPC)}

The total phenolic content (TPC) was determined according to the Folin-Ciocalteu method as described earlier [46] with the use of methanol/water $(70: 30, v / v)$ solutions of the tested extracts $(0.12-0.90 \mathrm{mg} / \mathrm{mL})$. Results were expressed as gallic acid equivalents (GAE) per dry weight of the extracts. 


\subsection{Biological Activity Testing}

\subsubsection{Reactive Oxygen Species Scavenging Tests}

The DPPH scavenging activity was determined based on the earlier optimized method [45] with the use of serial dilutions of the analytes $(2-160 \mu \mathrm{g} / \mathrm{mL})$ in methanol/water $(70: 30, v / v)$. Finally, the concentration of the analytes in the reaction medium (in $\mu \mathrm{g} / \mathrm{mL}$ ) was plotted against the percentage of remaining DPPH using the DPPH calibration curve, and the normalized EC50 values were calculated as described previously [47].

The xanthine/xanthine oxidase system with nitrobluetetrazolium (NBT) reduction, was used to determine the superoxide anion $\left(\mathrm{O}_{2}{ }^{--}\right)$scavenging capacity as described previously [48]. Prior to the analysis, the extracts were dissolved in a $\left(\mathrm{Ca}^{2+}\right)$-free PBS buffer to the concentrations of $2.5-400.0 \mu \mathrm{g} / \mathrm{mL}$. As a positive control, ascorbic acid was used. Finally, the $\mathrm{SC}_{50}$ values were calculated from the calibration curves. In order to assess the possibility of direct interaction of the tested analytes with xanthine oxidase, the uric acid production by the enzyme was monitored at $295 \mathrm{~nm}$ [49].

The hydrogen peroxide $\left(\mathrm{H}_{2} \mathrm{O}_{2}\right)$ scavenging capacity was tested by the horseradish peroxidase method as described previously [48]. Prior to the analysis, the extracts were dissolved in the $\left(\mathrm{Ca}^{2+}\right)$-free PBS buffer to the concentrations of $10-140 \mu \mathrm{g} / \mathrm{mL}$. As a positive control, quercetin was used. Finally, the $\mathrm{SC}_{50}$ values were calculated from the five-point calibration curves.

\subsubsection{Ferric Reducing Antioxidant Power (FRAP) Assay}

The FRAP was determined according to [30] with some variations [47]. Prior to the analysis, the analytes were diluted with methanol/water $(70: 30, v / v)$ to the concentrations of $40-360 \mu \mathrm{g} / \mathrm{mL}$. The activity was expressed in micromoles of ferrous ions produced by $1 \mathrm{~g}$ of the dry extract or standard, which value was calculated from the eight-point calibration curve of ferrous sulphate.

\subsubsection{Linoleic Acid Peroxidation Test (Ferric Thiocyanate Method, FTC)}

The ability of the analytes to inhibit AAPH-induced LA-peroxidation was assayed as described earlier [47] and with the use of serial dilutions of the analytes $(0.07-3.00 \mathrm{mg} / \mathrm{mL})$ in methanol/water $(70: 30, v / v)$. Finally, the $\mathrm{IC}_{50}$ values were calculated from the five-point concentration-inhibition calibration curve.

\subsubsection{Hyaluronidase and Lipoxygenase Inhibition Tests}

Inhibition of hyaluronidase was determined by the modified turbidimetric USP [50] with heparin used as a positive control. Prior to the assay, the analytes were dissolved in monosodium phosphate buffer ( $\mathrm{pH}=7.0$ ) with $0.01 \%$ BSA to the concentrations of $1-2 \mathrm{mg} / \mathrm{mL}$.

Inhibition of lipoxygenase was tested according to [48] with the use of serial dilutions of the analytes $(100-600 \mu \mathrm{g} / \mathrm{mL})$ in sodium borate buffer $(\mathrm{pH}=9.0)$. As a positive control, quercetin was used. Finally, the $\mathrm{IC}_{50}$ values were calculated from the five-point calibration curves. 


\subsection{Phytochemical Profiling}

\subsubsection{UHPLC-PDA-ESI-MS ${ }^{3}$ and HPLC-PDA Fingerprint Conditions}

The UHPLC-PDA-ESI-MS ${ }^{3}$ analysis was performed using an UHPLC-3000 RS system (Dionex, Dreieich, Germany) equipped with a dual low-pressure gradient pump, an autosampler, a column compartment, a diode array detector, and an AmaZon SL ion trap mass spectrometer with an ESI interface (Bruker Daltonik, Bremen, Germany). Separations were carried out on a Kinetex XB-C18 column $\left(1.7 \mu \mathrm{m}, 150 \mathrm{~mm} \times 2.1 \mathrm{~mm}\right.$ i.d.; Phenomenex, Torrance, CA, USA) at $25{ }^{\circ} \mathrm{C}$. The mobile phase (A) was water/acetonitrile/formic acid (95:5:0.1, v/v/v), and the mobile phase (B) was acetonitrile/formic acid $(100: 0.1, v / v)$. A linear gradient system was used for elution: 0-45 min, 6\%-26\% B (v/v); 45-55 min, 26\%-95\% B; 55-63 min, 95\% B; 63-70 min, 95\%-6\% B; 70-80 min, 6\% B (equilibration). The flow rate was $0.3 \mathrm{~mL} / \mathrm{min}$. Before injection, samples of the tested extracts $(10-40 \mathrm{mg})$ were dissolved in $70 \%$ $(v / v)$ aqueous methanol $(10 \mathrm{~mL})$ and filtered through a PTFE syringe filter $(13 \mathrm{~mm}, 0.2 \mu \mathrm{m}$, Whatman, Pittsburgh, PA, USA). UV-Vis spectra were recorded over a range of 200-600 nm, and chromatograms were acquired at $254 \mathrm{~nm}, 280$ and $350 \mathrm{~nm}$. LC eluate was introduced directly into the ESI interface without splitting and analyzed in a negative and positive ion mode. $\mathrm{MS}^{2}$ and $\mathrm{MS}^{3}$ fragmentations were obtained for the most abundant ions at the time. The nebulizer pressure was 40 psi; dry gas flow $9 \mathrm{~L} / \mathrm{min}$; dry temperature $300{ }^{\circ} \mathrm{C}$; and capillary voltage $4.5 \mathrm{kV}$. Analysis was carried out using scan from $\mathrm{m} / \mathrm{z} 200$ to 2200 .

The HPLC-PDA assays were carried out on a Waters 600E Multisolvent Delivery System (Waters, Milford, MA, USA) with a PDA detector (Waters 2998) detector scanning in the wavelength range of 220-450 nm; a model 7725 sample injection valve (Rheodyne, Pittsburgh, PA, USA); and a $5 \mu \mathrm{L}$ injection loop. A C18 Ascentis ${ }^{\circledR}$ Express column $(2.7 \mu \mathrm{m}, 75 \mathrm{~mm} \times 4.6 \mathrm{~mm}$ i.d.; Supelco, Bellefonte, PA, USA), guarded by a C18 Ascentis ${ }^{\circledR} \mathrm{C} 18$ Supelguard guard column $(3 \mu \mathrm{m}, 20 \mathrm{~mm} \times 4 \mathrm{~mm}$ i.d.; Supelco), was maintained at $30^{\circ} \mathrm{C}$ using a Jetstream Plus 5480 thermostat (Thermotechnic Products, Langenzersdorf, Austria). An injection volume of the samples (prepared as described above) was $5 \mu \mathrm{L}$. The analytical method was the same as applied previously for Sorbus extracts [47] with twelve external standards used for calibration including CA, ECA, CFA, CHA, $p$ CA, PCA, $p$ HBA, RT, HY, IQ, MQ, QU, and KA. Identification and peak purity tests were made with an automated match system (Waters Empower 2 PDA software). The tentatively identified peaks were quantified as equivalents of ECA (proanthocyanidins), PCA (hydroxybenzoic acids), CHA (chlorogenic acid isomers), CFA or $p$ CA (hydroxycinnamic acid derivatives other than CHAs, depending on their UV-Vis spectra), RT (flavonoid diglycosides, mean flavonoids eluting before RT), and IQ (flavonoid monoglycosides, mean flavonoids eluting after RT).

\subsubsection{Determination of Total Contents of Main Groups of Polyphenols (TPA and TFA)}

The total proanthocyanidin content (TPA) was quantified by the modified butanol-HCl assay as described previously [47] with the use of methanol/water $(70: 30, v / v)$ solutions of the tested extracts and fractions $(0.40-2.00 \mathrm{mg} / \mathrm{mL})$. The results were expressed as cyanidin chloride (CYE) equivalents per dry weight of the extracts. 
The total flavonoid content (TFA) was determined by HPLC-PDA as the total content of flavonoid aglycones after acid hydrolysis, according to [51] with some modifications. Samples of the extracts $(50-150 \mathrm{mg})$ were heated under reflux for three hours with $70 \%(v / v)$ aqueous methanol $(30 \mathrm{~mL})$ and $25 \%(w / v)$ hydrochloric acid $(9 \mathrm{~mL})$. The hydrolysate was diluted with methanol to $50 \mathrm{~mL}$, filtered through a PTFE syringe filter, and injected $(5 \mu \mathrm{L})$ into the HPLC system (see Section 3.5.1). The elution system consisted of solvent A $(0.5 \%$ water solution of orthophosphoric acid, $w / v)$ and solvent B (methanol), with the elution profile as follows: 0-2 min, 40\% B (v/v); 2-5.5 min, 40\%-60\% B; 5.5-6 min, $60 \%-40 \% \mathrm{~B} ; 6-10 \mathrm{~min}, 40 \% \mathrm{~B}$ (equilibration). The flow rate was $1.3 \mathrm{~mL} / \mathrm{min}$, and the column was maintained at $40{ }^{\circ} \mathrm{C}$. Aglycones were identified by PDA-spectra and detected at $370 \mathrm{~nm}$. Two external standards, QU and KA, were used for calibration.

\subsection{Statistical Analysis}

Results were reported as means \pm SD (standard deviation) of the indicated number of experiments. The statistics (calculation of SD, one-way analysis of variance, HSD Tukey's tests, and linearity studies) were performed using the software Statistica10Pl for Windows (StatSoft Inc., Krakow, Poland) with $p$ values less than 0.05 regarded as significant.

\section{Conclusions}

Leaves of $G$. procumbens contain considerable quantities of antioxidant polyphenols, which can be effectively extracted with $75 \%(v / v)$ aqueous methanol and further concentrated by ethyl acetate. The obtained extracts possess significant and dose-dependent SET- and HAT-type antioxidant capacities in vitro, as well as moderate anti-inflammatory activity, which correlate with their phenolic composition. Among the phenolic constituents, low- and medium-molecular-weight proanthocyanidins and phenolic acids are primarily responsible for the tested antioxidant capacity, whereas flavonoids are the main determinants of the anti-inflammatory effects. Regarding the potent activity of Gaultheria extracts in comparison with phenolic standards, the results of the present study partly explain the ethnobotanical use of the plant and support the idea that Ericaceae leaves may be good sources of beneficial prophylactic phenolic antioxidants with anti-inflammatory potential. However, further research is needed to confirm the present results in cell-based or in vivo studies, and to investigate in detail the dominant phenolic constituents of the analyzed extracts, especially proanthocyanidins, in terms of their structure and biological effects at molecular levels.

\section{Supplementary Materials}

Supplementary materials can be accessed at: http:/www.mdpi.com/1420-3049/19/12/20498/s1.

\section{Acknowledgments}

This work was financially supported by the Medical University of Lodz (grants Nos. 502-34-010, 503/3-022-01/503-01, and 503/3-022-01/503-06-300). 


\section{Author Contributions}

PM and MAO designed research and analyzed the data; PM, AD and AB performed antioxidant activity studies; PM, JPP and AB performed anti-inflammatory activity studies; PM, SG, AK, AO and MAO performed phytochemical studies; MAO, AO and PM wrote the paper. All authors read and approved the final manuscript.

\section{Conflicts of Interest}

The authors declare no conflict of interest.

\section{References}

1. Prakash, D.; Kumar, N. Cost effective natural antioxidants. In Nutrients, Dietary Supplements, and Nutriceuticals: Cost Analysis Versus Clinical Benefits, 1st ed.; Watson, R.R., Gerald, J.K., Preedy, V.R., Eds.; Humana Press: New York, NY, USA, 2011; pp. 163-187.

2. Giampieri, F.; Alvarez-Suarez, J.M.; Battino, M. Strawberry and human health: Effects beyond antioxidant activity. J. Agric. Food Chem. 2014, 62, 3867-3876.

3. Battino, M.; Beekwilder, J.; Denoyes-Rothan, B.; Laimer, M.; McDougall, G.J.; Mezzetti, B. Bioactive compounds in berries relevant to human health. Nutr. Rev. 2009, 67 (Suppl. S1), S145-S150.

4. Brown, E.M.; Latimer, C.; Allsopp, P.; Ternan, N.G.; McMullan, G.; McDougall, G.J.; Stewart, D.; Crozier, A.; Rowland, I.; Gill, C.I.R. In vitro and in vivo models of colorectal cancer: Antigenotoxic activity of berries. J. Agric. Food Chem. 2014, 62, 3852-3866.

5. Rodriquez-Mateos, A.; Heiss, C.; Borges, G.; Crozier, A. Berry (poly)phenols and cardiovascular health. J. Agric. Food Chem. 2014, 62, 3842-3851.

6. Sharma, J.V.; Edirisinghe, I.; Burton-Freeman, B.M. Berries: Anti-inflammatory effects in humans. J. Agric. Food Chem. 2014, 62, 3886-3903.

7. Zheng, W.; Wang, S.Y. Oxygen Radical Absorbing Capacity of phenolics in blueberries, cranberries, chokeberries, and lingonberries. J. Agric. Food Chem. 2003, 51, 502-509.

8. Ehlenfeldt, M.K.; Prior, R.L. Oxygen Radical Absorbance Capacity (ORAC) and phenolic and anthocyanin concentrations in fruit and leaf tissues of highbush blueberry. J. Agric. Food Chem. 2001, 49, 2222-2227.

9. Pavlović, R.D.; Lakusić, B.; Doslov-Kokorus, Z.; Kovacević, N. Arbutin content and antioxidant activity of some Ericaceae species. Pharmazie 2009, 64, 656-659.

10. Mechikova, G.Y.; Kuzmich, A.S.; Ponomarenko, L.P.; Kalinovsky, A.I.; Stepanova, T.A.; Fedorov, S.N.; Stonik, V.A. Cancer-preventive activities of secondary metabolites from leaves of the bilberry Vaccinium smallii A. Gray. Phytother. Res. 2010, 24, 1730-1732.

11. Oliveira, I.; Coelho, V.; Baltasar, R.; Pereira, J.A.; Baptista, P. Scavenging capacity of strawberry tree (Arbutus unedo L.) leaves on free radicals. Food Chem. Toxicol. 2009, 47, 1507-1511.

12. Middleton, D.J. Infrageneric classification of the genus Gaultheria L. (Ericaceae). Bot. J. Linn. Soc. 1991, 106, 229-258. 
13. Zhang, D.; Liu, R.; Sun, L.; Huang, C.; Wang, C.; Zhang, D.M.; Zhang, T.T.; Du, G.H. Anti-inflammatory activity of methyl salicylate glycosides isolated from Gaultheria yunnanensis (Franch.) Rehder. Molecules 2011, 16, 3875-3884.

14. Nikolić, M.; Marković, T.; Mojović, M.; Pejin, B.; Savić, A.; Perić, T.; Mojović, D.; Stević, T.; Soković, M. Chemical composition and biological activity of Gaultheria procumbens L. essential oil. Ind. Crops Prod. 2013, 49, 561-567.

15. Garcia-Lafuente, A.; Guillamon, E.; Villares, A.; Rostagno, M.A.; Martinez, J.A. Flavonoids as anti-inflammatory agents: Implications in cancer and cardiovascular disease. Inflamm. Res. 2009, 58, 537-552.

16. Li, W.G.; Zhang, X.Y.; Wu, Y.J.; Tian, X. Anti-inflammatory effect and mechanism of proanthocyanidins from grape seeds. Acta Pharmacol. Sin. 2001, 22, 1117-1120.

17. Youn, J.; Lee, K.H.; Won, J.; Huh, S.J.; Yun, H.S.; Cho, W.G.; Paik, D.J. Beneficial effects of rosmarinic acid on suppression of collagen induced arthritis. J. Rheumatol. 2003, 30, 1203-1207.

18. Dai, J.; Mumper, R.J. Plant phenolics: Extraction, analysis and their antioxidant and anticancer properties. Molecules 2010, 15, 7313-7352.

19. Matkowski A. Plant phenolic metabolites as antioxidants and mutagenesis inhibitors. In Cell Biology and Instrumentation: UV Radiation, Nitric Oxide and Cell Death in Plants, 1st ed.; Blume, Y., Durzan, D.J., Smertenko, P., Eds.; IOS Press: Amsterdam, The Netherlands, 2006; pp. 129-148.

20. Saleem, A.; Harris, C.S.; Asim M.; Cuerrier, A.; Martineau, L.; Haddad, P.S.; Arnason, J.T. A RP-HPLC-DAD-APCI/MSD method for the characterization of medicinal Ericaceae used by the Eeyou Istchee Cree first nations. Phytochem. Anal. 2010, 21, 328-339.

21. McCune, L.M.; Johns, T. Antioxidant activity in medicinal plants associated with the symptoms of diabetes mellitus used by the Indigenous Peoples of the North American boreal forest. J. Ethnopharmacol. 2002, 82, 197-205.

22. Manach, C.; Williamson, G.; Morand, C.; Scalbert, A.; Rémésy, C. Bioavailability and bioefficacy of polyphenols in humans. I. Review of 97 bioavailability studies. Am. J. Clin. Nutr. 2005, 81, 230S-242S.

23. Capasso, F.; Gaginella, T.S.; Grandolini, G.; Izzo, A.A. Phytotherapy-A Quick Reference to Herbal Medicine, 13th ed.; Springer Verlag: Berlin/Heidelberg, Germany, 2003; pp. 45-60.

24. Prior, R.L.; Wu, X.; Schaich, K. Standardized methods for the determination of antioxidant capacity and phenolics in foods and dietary supplements. J. Agric. Food Chem. 2005, 53, 4290-4302.

25. Kneifel, W.; Czech, E.; Kopp, B. Microbial contamination of medicinal plants-a review. Planta Med. 2002, 68, 5-15.

26. Ling, L.T.; Radhakrishnan, A.K.; Subramaniam, T.; Cheng, H.M.; Palanisamy, U.D. Assessment of antioxidant capacity and cytotoxicity of selected Malaysian plants. Molecules 2010, 15, 2139-2151.

27. Erol, N.T.; Sari, F.; Calikoglu, E.; Velioglu, Y.S. Green and roasted mate: phenolic profile and antioxidant activity. Turk. J. Agric. For. 2009, 33, 353-362.

28. Bazylko, A.; Parzonko, A.; Jeż, W.; Osińska, E.; Kiss, A.K. Inhibition of ROS production, photoprotection, and total phenolic,flavonoids and ascorbic acid content of fresh herb juice and extractsfrom the leaves and flowers of Tropaeolum majus. Ind. Crops Prod. 2014, 55, 19-24. 
29. Buetler, T.M.; Krauskopf, A.; Ruegg, U.T. Role of superoxide as a signaling molecule. Physiology 2004, 19, 120-123.

30. Pulido, R.; Bravo, L.; Saura-Calixto, F. Antioxidant activity of dietary polyphenols as determined by a modified ferric reducing/antioxidant power assay. J. Agric. Food Chem. 2000, 48, 3396-3402.

31. Termentzi, A.; Kefalas, P.; Kokkalou, E. Antioxidant activities of various extracts and fractions of Sorbus domestica fruit at different maturity stages. Food Chem. 2006, 98, 599-608.

32. Peyrat-Maillard, M.N.; Cuvelier, M.E.; Berset, C. Antioxidant activity of phenolic compounds in 2,2'-azobis (2-amidinopropane) dihydrochloride (AAPH)-induced oxidation: Synergistic and antagonistic effects. J. Am. Oil Chem. Soc. 2003, 80, 1007-1012.

33. Bellick, Y.; Boukraâ, L.; Alzahrani, H.A.; Bakhotmah, B.A.; Abdellah, F.; Hammoudi, S.M.; Igeur-Ouada, M. Molecular mechanism underlying anti-inflammatory and anti-allergic activities of polyphenols: An update. Molecules 2013, 18, 322-353.

34. Clifford, M.N.; Johnston, K.L.; Knight, S.; Kuhnert, N. Hierarchical scheme for LC-MS ${ }^{n}$ identification of chlorogenic acids. J. Agric. Food Chem. 2003, 51, 2900-2911.

35. Nagels, L.; van Dongen, W.; de Brucker, J.; de Pooter, H. High-performance liquid chromatographic separation of naturally occuring esters of phenolic acids. J. Chromatogr. A 1980, 187, 181-187.

36. Su, S.; Cui, W.; Zhou, W.; Duan, J.; Shang, E.; Tang, Y. Chemical fingerprint and quantitative constituent analysis of Siwu decoction categorized formule by UPLC-QTOF/MS/MS and HPLC-DAD. Chin. Med. 2013, 8, 1-15.

37. Li, S.; Xiao, J.; Chen, L.; Hu, C.; Chen, P.; Xie, B.; Sun, Z. Identification of A-series oligomeric procyanidins from pericarp of Litchi chinensis by FT-ICR-MS and LC-MS. Food Chem. 2012, 135, 31-38.

38. Fabre, N.; Rustan, I.; de Hoffmann, E.; Quetin-Leclercq, J. Determination of flavone, flavonol, and flavanone aglycones by negative ion liquid chromatography electrospray ion trap mass spectrometry. J. Am. Soc. Mass Spectrom. 2001, 12, 707-715.

39. Perestrelo, R.; Lu, Y.; Santos, S.A.O.; Silvestre, A.J.D.; Neto, C.P.; Camara, J.S.; Rocha, S.M. Phenolic profile of Sercial and Tinta Negra Vitis vinifera L. grape skins by HPLC-DAD-ESI-MS ${ }^{\mathrm{n}}$. Novel phenolic compounds in Vitis vinifera L. grape. Food Chem. 2012, 135, 94-104.

40. Li, H.; Ma, Q.; Liu, Y.; Qian, J.; Zhou, J.; Zhao, Y. Chemical constituents from Polygonum perfoliatum. Chin. J. Appl. Environ. Biol. 2009, 15, 615-620.

41. Liu, W.R.; Qiao, W.L.; Liu, Z.Z.; Wang, X.H.; Jiang, R.; Li, S.Y.; Shi, R.B.; She, G.M. Gaultheria: Phytochemical and pharmacological characteristics. Molecules 2013, 18, 12071-12108.

42. Santos-Buelga, C.; Scalbert, A. Proanthocyanidins and tannin-like compounds-Nature, occurrence, dietary intake and effects on nutrition and health. J. Sci. Food Agric. 2000, 80, 1094-1117.

43. Yokozawa, T.; Chen, C.P.; Dong, E.; Tanaka, T.; Nonaka, G.I.; Nishioka, I. Study on the inhibitory effect of tannins and flavonoids against the 1,1-diphenyl-2-picrylhydrazyl radical. Biochem. Pharmacol. 1998, 56, 231-222.

44. Guo, X.D.; Zhang, D.Y.; Gao, X.J.; Parry, J.; Liu, K.; Liu, B.L.; Wang, M. Quercetin and quercetin-3-O-glucuronide are effective in ameliorating endothelial insulin resistance through inhibition of reactive oxygen species-associated inflammation. Mol. Nutr. Food Res. 2013, 57, 1037-1045. 
45. Olszewska, M.; Wolbiś, M. Further flavonoids from the flowers of Prunus spinosa L. Acta Pol. Pharm. 2002, 59, 133-137.

46. Olszewska, M.A.; Michel, P. Antioxidant activity of inflorescences, leaves and fruits of three Sorbus species in relation to their polyphenolic composition. Nat. Prod. Res. 2009, 23, 1507-1521.

47. Olszewska, M.A.; Presler, A.; Michel, P. Profiling of phenolic metabolites and antioxidant activity of dry extracts from the selected Sorbus species. Molecules 2012, 17, 3093-3113.

48. Granica, S.; Czerwińska, M.E.; Piwowarski, J.P.; Ziaja, M.; Kiss, A.K. Chemical composition, antioxidative and anti-inflammatory activity of extracts prepared from aerial parts of Oenothera biennis L. and Oenothera paradoxa Hudziok obtained after seeds cultivation. J. Agric. Food Chem. 2013, 61, 801-810.

49. Schepetkin, I.A.; Kirpotina, L.N.; Jakiw, L.; Khlebnikov, A.I.; Blaskovich, C.L.; Jutila, M.A.; Quinn, M.T. Immunomodulatory activity of oenothein B isolated from Epilobium angustifolium. J. Immunol. 2009, 83, 6754-6766.

50. Piwowarski, J.P.; Kiss, A.K.; Kozłowska-Wojciechowska, M. Anti-hyaluronidase and anti-elastase activity screening of tannin-rich plant materials used in traditional Polish medicine for external treatment of diseases with inflammatory background. J. Ethnopharmacol. 2011, 137, 937-941.

51. Olszewska, M. Quantitative HPLC analysis of flavonoids and chlorogenic acid in the leaves and inflorescences of Prunus serotina Ehrh. Acta Chromatogr. 2007, 19, 253-269.

Sample Availability: Samples of the dry leaf extracts are available from the authors.

(C) 2014 by the authors; licensee MDPI, Basel, Switzerland. This article is an open access article distributed under the terms and conditions of the Creative Commons Attribution license (http://creativecommons.org/licenses/by/4.0/). 